Published in final edited form as:

Cancer Res. 2016 November 1; 76(21): 6396-6409. doi:10.1158/0008-5472.CAN-16-0225.

\title{
EGFL6 regulates the asymmetric division, maintenance and metastasis of ALDH+ ovarian cancer cells
}

\author{
Shoumei Bai ${ }^{1}$, Patrick Ingram ${ }^{2}$, Yu-Chih Chen ${ }^{2}$, Ning Deng ${ }^{1}$, Alex Pearson ${ }^{1}$, Yashar \\ Niknafs ${ }^{1}$, Patrick O'Hayer ${ }^{1}$, Yun Wang ${ }^{1}$, Zhong-Yin Zhang ${ }^{4}$, Elisa Boscolo ${ }^{5}$, Joyce \\ Bischoff $^{6}$, Euisik Yoon ${ }^{2}$, and Ronald J Buckanovich ${ }^{1,3}$ \\ ${ }^{1}$ Division of Hematology-Oncology, Dept. of Internal Medicine, University of Michigan, Ann Arbor, \\ Michigan \\ ${ }^{2}$ Dept. of Electrical Engineering, University of Michigan, Ann Arbor, Michigan \\ ${ }^{3}$ Division of Gynecologic-Oncology, Dept. of Obstetrics and Gynecology, University of Michigan, \\ Ann Arbor, Michigan \\ ${ }^{4}$ Dept. of Biochemistry and Molecular Biology, Indiana University School of Medicine \\ ${ }^{5}$ Dept. of Pediatrics, Cincinnati Children's Hospital Medical Center, Cincinnati Ohio \\ ${ }^{6}$ Dept. of Surgery, Boston Children's Hospital and Harvard Medical School, Boston, MA
}

\begin{abstract}
Little is known about the factors that regulate the asymmetric division of cancer stem-like cells. Here we demonstrate that EGFL6, a stem cell regulatory factor expressed in ovarian tumor cells and vasculature, regulates ALDH+ ovarian cancer stem-like cells (CSC). EGFL6 signaled at least in part via the oncoprotein SHP2 with concomitant activation of ERK. EGFL6 signaling promoted the migration and asymmetric division of ALDH+ ovarian CSC. As such, EGFL6 increased not only tumor growth but also metastasis. Silencing of EGFL6 or SHP2 limited numbers of ALDH+ cells and reduced tumor growth, supporting a critical role for EGFL6/SHP2 in ALDH+ cell maintenance. Notably, systemic administration of an EGFL6-neutralizing antibody we generated restricted tumor growth and metastasis, specifically blocking ovarian cancer cell recruitment to the ovary. Together, our results offer a preclinical proof of concept for EGFL6 as a novel therapeutic target for the treatment of ovarian cancer.
\end{abstract}

\section{Keywords}

EGFL6; SHP2; Cancer Stem-like cell; Tumor endothelial cell; Ovarian Cancer; Asymmetric division

\footnotetext{
Contact. ronaldbu@med.umich.edu, Phone: 1-734-764-2395, Fax: 1-734-647-9654.

Conflict of interest: None
} 


\section{Introduction}

While controversy persists regarding cancer stem-like cells (CSC), ALDH-expressing CSC have been linked with ovarian cancer chemotherapy resistance, disease recurrence (1-4) and metastasis (5). We reported an epithelial ovarian cancer (EOC) cell differentiation hierarchy consistent with a CSC model (1). Within this hierarchy, $\mathrm{ALDH}^{+} \mathrm{CD} 133^{+}$cells and $\mathrm{ALDH}^{+} \mathrm{CD} 133^{-}$cells have the greatest cancer initiating capacity (2) indicating that $\mathrm{ALDH}^{+}$ cells are important for ovarian cancer biology.

Normal stem cells are closely associated with vascular cells in a "stem cell niche" $(6,7)$. Like normal stem cells, CSC reside in a perivascular location (8)(9). Tumor vascular cells secrete "angiocrine" factors (10) which promote stem cell proliferation. Little is known about the vascular factors that regulate CSC. Two studies identified EGFL6 in tumor vascular cells of EOC $(11,12)$. EGFL6 is a secreted protein (13) which regulates stem cell proliferation and differentiation in different biologic systems. EGLF6 regulates stems cells in hair follicle morphogenesis $(14,15)$, stimulates endothelial cell migration/proliferation in a p-ERK-dependent manner during osteoblast differentiation (16), and promotes the adhesion and proliferation of stromal vascular cells during adipocyte differentiation and (17).

Herein we evaluate the role of EGFL6 in ovarian cancer. We find EGFL6 is expressed in tumor vascular cells and in some cancer cells. We demonstrate in vitro that EGFL6 induces $\mathrm{ALDH}^{+}$ovarian CSC to undergo asymmetric division. EGFL6 signaling is mediated in part via integrin-dependent activation of the phosphatase SHP2 and pERK. EGFL6 or SHP2 knockdown/inhibition is associated with a significant reduction in $\mathrm{ALDH}^{+}$cells and a reduction in tumor growth. EGFL6 expression in vascular cells increases tumor growth and metastasis. EGFL6 blockade reduces cancer growth and reduces metastasis. Interestingly, EGFL6 blockade completely eliminated metastases to the ovary, suggesting that EGFL6 might play a critical role in the recruitment of cancer cells to the ovary. Together, our results indicate that EGFL6 is a novel tumor and angiocrine factor that regulates $\mathrm{ALDH}^{+}$cell asymmetric division, migration, and metastasis. EGFL6 thus represents a potential therapeutic target in ovarian cancer.

\section{Materials and Methods}

\section{Primary tumor processing}

All studies were approved by the IRB of the University of Michigan, and tumors were obtained with informed patient consent. All tumors were stage III or IV high grade serous ovarian or primary peritoneal cancer (HGSC). Single-cell isolation from tumor tissues and ascites were as described $(2,18)$.

\section{Cell culture, tumor sphere culture and treatment}

Culture methods are detailed in supplemental methods.

\section{Quantitative real-time PCR (qRT-PCR)}

cDNA synthesis, PCR and primer information are described in supplemental methods. 


\section{TMA staining}

A tissue microarray (TMA) contained primary debulking tissues from 154 chemotherapynaïve ovarian cancer patients. $12.5 \%, 10.7 \%, 66.1 \%$, and $10.7 \%$ patients had stage I-IV disease, respectively. Median age was 58 years (minimum, 30; maximum, 84). TMA sections were processed as described (2) with two anti-EGL6 antibodies (Sigma, 1:200; and a mouse anti-EGFL6 we generated, 1:400). Tumors were scored by two reviewers. Tumors were scored as EGFL6 ${ }^{+}$if vascular EGFL6 expression was detected in either primary tumor or metastatic sites. The method of Kaplan and Meier was used to estimate overall and recurrence-free survival. Follow-up time was calculated from the date of diagnosis/staging surgery until the date of first documented relapse or death. Data was censored at 5 years. The log-rank test was conducted to test for a significant difference $(\mathrm{p}<0.05)$ between groups. We used the Cox proportional hazards model to assess individual variable effect on time-toevent outcome. Statistical programming was performed using R version 3.0.1.

\section{Bioinformatics}

For EGFL6-expression analysis in normal ovary and different ovarian cancer histologies, gene expression data were obtained from ONCOMINE (gene accession \#NM_015507, Probe ID 219454_at, Hendrix dataset, Affymetrix HG_U133A array) (20). Detailed methodologies are provided in supplemental methods.

\section{EGFL6-expressing cell lines}

EGFL6 was cloned into p3xFlag and pRSV-GFP vectors. SKOV3 cells were transfected with EGFL6-p3xFLAG using FuGene 6 reagent (Promega) per protocol. EGFL6-expressing clones were selected by G418 treatment and confirmed by Western blotting with Flag antibody. Transduced cell lines expressing EGFL6 or control were obtained by lentiviral infection followed by FACS sorting of GFP-positive cells.

\section{EGFL6 production}

HEK293 cells were transiently transfected with EGFL6 or empty vector plasmid using FuGENE 6 reagent as above in RPMI-5\% FBS. Supernatant was collected at 72hrs, EGFL6 secretion was confirmed via Western blotting analysis, and supernatant used for cell treatment. For purification, cell lysates of transiently transfected HEK293 cells were loaded onto the FLAG M2 Affinity Gel (Sigma) column under gravity flow 4C, washed with TBS, and FLAG-EGFL6 protein eluted with $0.1 \mathrm{M}$ glycine $\mathrm{HCl}, \mathrm{pH} 3.5$, and neutralized with $1 \mathrm{M}$ Tris, $\mathrm{pH}$ 8.0. Unless otherwise indicated, EGFL6 treatment in in vitro studies was daily for $72 \mathrm{hr}$.

\section{Cell cycle analysis}

SKOV3 cells were synchronized by serum starvation for 24hr, treated with EGFL6 or control for $24 \mathrm{hr}$, fixed with ice-cold ethanol and washed with PBS, then stained with propidium iodide $(10 \mathrm{mg} / \mathrm{ml})$ and RNase-A $(100 \mathrm{ug} / \mathrm{ml})$ in PBS FACS analyzed by FlowJo. 


\section{Flow Cytometry and Fluorescence-associated cell sorting (FACS)}

FACS assay was performed. Briefly, SKOV3 cells or primary ovarian tumor/ascites cells were stained with DAPI and ALDEFLUOR (Stem Cell Technologies) as previously described (2). For FACS isolation, equal numbers of $\mathrm{ALDH}^{+}$and $\mathrm{ALDH}^{(-)}$cells were collected for subsequent experiments.

\section{Microfluidics Culture}

Cells were FACS-isolated and loaded into the microfluidics device as previously described (21) and photographed to confirm ALDH expression. 12hr after loading, cells were treated with every $12 \mathrm{hr}$ EGFL6 or vehicle. After $48 \mathrm{hr}$ or $96 \mathrm{hr}$ of treatment (cell lines vs. primary cells, respectively), cells were re-stained with ALDEFLUOR in situ and photographed. All samples were evaluated in at least two replicate devices from at least two experiments. A student's t-test was used to compare results for each sample. ANOVA analysis was used to determine statistically significant findings of aggregate analyses.

Microfluidic migration assays were performed in RPMI-5\% FBS as previously described (22). Loading was photographed to confirm cell location. EGFL6-containing media or control media was provided in right inlet. Chips were re-imaged after $24 \mathrm{hr}$ and distance migrated measured. Results presented represent means \pm standard deviations. A two-tailed student t-test (unpaired) was used to measure significance.

\section{Immunohistochemistry (IHC) and Immunofluorescence (IF)}

Experiments performed as previously described (2)(23). The primary antibodies are provided in supplemental methods.

\section{Western Blotting}

Cells were lysed in NP40 cell lysis buffer. Antibodies used are provided in the supplemental methods.

\section{EGFL6 antibody purification and treatment}

Hybridoma cells were maintained in RPMI-5\% FBS. Supernatant was collected after $\sim 7$ days, cells/debris were removed by centrifugation, and supernatant loaded on Protein $G$ Agarose (Millipore), washed, and antibody eluted with $50 \mathrm{mM}$ glycine PH.2.7, neutralized to PH 7.2-7.4 with 1M Tris (Ph 9.0). EGFL6 antibody was applied at $10 \mu \mathrm{g} / \mathrm{ml}$ for in vitro cell treatment and $10 \mathrm{mg} / \mathrm{kg}$ twice weekly for in vivo treatment.

\section{EGFL6 and SHP2 shRNA knockdown}

EGFL6 or SHP2 shRNA (Sigma) and control scrambled shRNA were co-transfected with Pspax2 and pMD2.G lentiviral packaging plasmids into HEK293T to produce lentivirus. NIHOVCAR3 or SKOV3 cells were transduced with shRNAs targeting EGFL6 or SHP2 or control, and selected with puromycin. RNA and cell lysates were prepared to confirm EGFL6 or SHP2 knockdown via qRT-PCR and Western blot. 


\section{Murine Tumor Models}

Animal experiments were approved by the University Committee for Use and Care of Animals. For transfected EGFL6-SKOV3 tumor model, three G418-selected EGFL6SKOV3 clones or three empty-vector clones, at $1 \times 10^{6}$ each, were injected into mouse axilla. Tumor volume was monitored weekly and mice were euthanized when tumors reached $\sim 1,000 \mathrm{~mm}^{3}$ (using LxWxW/2 calculation). EGFL6 $6^{\text {shRNA }}$ or scrambled ${ }^{\text {shRNA }}$ control cells $\left(1 \times 10^{6}\right.$ SKOV 3 or $1 \times 10^{6}$ NIHOVCAR 3$)$ were injected and tumors monitored as above. For intraperitoneal (IP) tumor models, $5 \times 10^{5}$ SKOV 3 cells were injected IP into NSG mice. Mice were treated with $\mathrm{mIgG}$ or anti-EGFL6 biweekly, as above. Mice were sacrificed when IP tumor nodules reached $\sim 400 \mathrm{~mm}^{3}$ or mice had significant weight gain/loss due to tumor/ ascites burden. At the time of euthanasia, mice were inspected for gross metastasis. Lung, liver, ovary and omentum/intestines were resected for histologic analysis of metastatic disease. For intravenous tumor cell injection, mice were mock-treated or treated with antiEGFL6blocking antibody for 3 days prior to tumor cell injection. SKOV3 cells $\left(1 \times 10^{6}\right)$ with $\mathrm{mIgG}$ or anti-EGFL6 were injected via tail vein into NSG mice. Therapy was maintained for 2 weeks after tumor cell injection. Mice were monitored, euthanized, and metastases assessed as described above.

\section{Establishment of HemSCEGFL6 tumor model}

HemSC were transduced with EGFL6-pRSVGFP or control lentivirus and FACS-sorted based on GFP expression. EGFL6 expression was confirmed by Western blot. Lucif-SKOV3 cells $\left(2 \times 10^{5}\right)$ were mixed with EGFL6-expressing HemSC $\left(\mathrm{HemSC}^{\text {EGFL6 }}, 1 \times 10^{6}\right)$ or control HemSC (HemSCControl). For primary cell-derived tumors, $5 \times 10^{5}$ primary cells (from 2 patients, injected bilaterally in 4 mice) were mixed with either $5 \times 10^{5} \mathrm{HemSC}^{\text {EGFL } 6}$ or $5 \times 10^{5}$

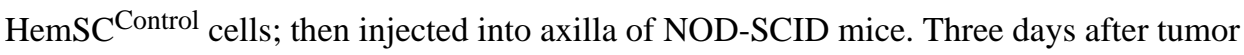
injection, mice were treated with $\mathrm{mIgG}$ or EGFL6 antibody $(5 \mathrm{mg} / \mathrm{kg}$ ) bi-weekly. At the time of euthanasia, SKOV3 flank tumors were resected and luciferase imaging was performed to identify microscopic metastases. From all animals, lung, liver, ovary, and omentum/ intestines were resected for histologic analysis of metastatic disease.

\section{Results}

\section{EGFL6 is up-regulated in ovarian cancer and predicts a poor patient prognosis}

We analyzed EGFL6 mRNA expression across ovarian cancer histologies in two different datasets (20). Compared to normal ovary, EGFL6 mRNA levels are significantly elevated in all ovarian tumor histologies, but are greatest in high grade serous cancers (HGSC) (Fig. 1A). We next stained a TMA of 154 ovarian tumors with EGFL6 antibody. EGFL6 protein was detected in tumor endothelial cells in $\sim 80 \%$ of tumors (Fig. 1B, C). EGFL6 was also detected in tumor-associated adipose (Fig. 1B) and, surprisingly, in cancer cells in $25 \%$ of tumors evaluated (Fig. 1B). EGFL6 expression in cancer cells was primarily in HGSC tumors, while EGFL6 expression in other histologies was primarily in the stroma (Supplemental Fig. 1A).

Based on prior studies, tumor cell EGFL6 expression was unexpected. However, analysis of EGFL6 expression in human ovarian cancer cell lines using the Cancer Cell Line 
Encyclopedia (CCLE) supported EGFL6 expression in many HGSC cell lines (Supplemental Fig. 1B). qRT-PCR analysis of HGSC cell lines confirmed clear expression of EGFL6 in NIHOVCAR3 and OVKATE HGSC cells (Fig. 1D). Little or no expression was noted in other ovarian cancer lines, including SKOV3 and CAOV3 cells.

Using the TMA, we scored vascular EGFL6 expression as present/absent in each tumor and performed univariate proportional hazards regression analysis to determine if vascular EGFL6 protein expression was a prognostic factor for ovarian cancer. EGFL6 expression was related both to death (hazard ratio $=3.91, \mathrm{p}=0.01$ ) and recurrence (hazard ratio $=2.67$, $\mathrm{p}=0.01$ ) (Fig. 1E). Multiple proportional hazards regression demonstrated no dependence between EGFL6 and age, stage, tumor grade, or debulking status.

We next screened RNAseq data from 261 serous ovarian carcinomas (TCGA) and investigated the correlation of expression of EGFL6 to all other genes in the genome. A pvalue cutoff (1e-8) was applied to generate a list of the 538 most correlated genes. Numerous tumor vascular-specific genes (including MXRA, TDO2, TNFAIP6, SEMA3D, and Coll11A1) and EGF-like genes (including EGFLAM and MEGF10) were highly correlated with EGFL6 expression. GSEA demonstrated that EGFL6-correlated genes were strongly correlated with invasive ovarian cancer and embryonic stem cell core genes (Fig. 1F and Supplemental Fig.1C).

\section{EGFL6 induces ovarian cancer cell proliferation}

We expressed EGFL6 in non-EGFL6-expressing cell lines, including HEK293 cells, NIH3T3 cells, and SKOV3 ovarian cancer cells. Western blot confirmed secretion of EGLF6 in both transient and stable transfectants (Fig. 2Ai). We purified EGFL6 protein to $>95 \%$ purity (Fig. 2Aii) and treated ovarian cancer cells with either purified EGFL6, supernatant from EGFL6-expressing HEK293 cells, or supernatant from control-transfected HEK293 cells. Purified fusion protein and supernatant from EGFL6-transfected cells had similar effects. EGFL6 treatment of SKOV3, OVCAR3, OVCAR8, and primary ovarian tumor cells was associated with a 30-40\% increase in total cell number (Fig. 2B). Cell cycle analysis demonstrated that EGFL6 treatment resulted in a 1.8-fold decrease in the number of cells in G1 phase and a concomitant increase in the number of cells in S and G2/M phases (Fig. 2C).

\section{EGFL6 Promotes Asymmetric Division of $\mathrm{ALDH}^{+}$Ovarian CSC}

Given GSEA correlation of EGFL6 with a core stem cell signature, we assessed the impact of EGFL6 on ovarian CSC. Aldehyde dehydrogenase enzymatic activity (ALDH) is an established marker of ovarian CSC $(2-4,24,25)$. Treatment of ovarian cancer cells with increasing concentrations of EGFL6 was associated with increasing total cell numbers, but decreasing percentages of $\mathrm{ALDH}^{+} \mathrm{CSC}$, with a resultant stable absolute $\mathrm{ALDH}^{+} \mathrm{CSC}$ number (Fig. 3A,B).

A dividing $\mathrm{ALDH}^{+} \mathrm{CSC}$ can theoretically undergo at least three distinct types of cell division related to the expression of ALDH: (i) division yielding $2 \mathrm{ALDH}^{+}$cells, (ii) differentiation yielding $2 \mathrm{ALDH}^{(-)}$cells, or (iii) asymmetric division yielding an $\mathrm{ALDH}^{+}$ cell (self-maintenance) and an $\mathrm{ALDH}^{(-)}$cell. The finding that EGFL6 increases total cancer cell number and decreases the percentage of $\mathrm{ALDH}^{+}$cells without impacting the absolute 
number of $\mathrm{ALDH}^{+}$cells is consistent with EGFL6 stimulating $\mathrm{ALDH}^{+} \mathrm{CSC}$ asymmetric division. Alternatively, EGFL6 could preferentially promote proliferation of $\mathrm{ALDH}^{(-)}$cells. We used single cell microfluidic culture (26) to evaluate EGFL6 impact on asymmetric divison. We FACS-sorted $\mathrm{ALDH}^{+}$and $\mathrm{ALDH}^{(-)} \mathrm{SKOV} 3$ cells into separate microfluidic devices and confirmed ALDH expression (Fig. 3Ci left panels). Cells were then mocktreated or treated with EGFL6. After 48 hours, live cells were re-stained/imaged with ALDEFLUOR (Fig. 3Ci, right panels). Cell divisions, type of daughter cells ( $\mathrm{ALDH}^{(-)}$or $\mathrm{ALDH}^{+}$), and total cell number were scored. 35\% of untreated ALDH ${ }^{(-)}$SKOV3 cells demonstrated no cell division while $65 \%$ of cells underwent division to produce additional $\mathrm{ALDH}^{(-)}$cells, to yield an average 2.2 daughter cells/well after 72 hours (Fig. 3Cii). No $\mathrm{ALDH}^{+}$daughter cells were observed. EGFL6 treatment of $\mathrm{ALDH}^{(-)}$SKOV3 cells had no significant impact on the number or type of cell divisions (Fig. 3Cii).

Compared to $\mathrm{ALDH}^{(-)}$cells, $\mathrm{ALDH}^{+}$SKOV3 cells were more proliferative, with only $10 \%$ of untreated cells not dividing. Consistent with prior studies, $\mathrm{ALDH}^{+}$cells demonstrated the ability to produce both $\mathrm{ALDH}^{+}$and $\mathrm{ALDH}^{(-)}$cells. $\mathrm{ALDH}^{+}$cells could divide to yield two $\mathrm{ALDH}^{+}$cells (symmetric division relative to ALDH), or undergo an asymmetric division yielding one $\mathrm{ALDH}^{+}$cell and an $\mathrm{ALDH}^{(-)}$cell. EGFL6 treatment of $\mathrm{ALDH}^{+} \mathrm{SKOV} 3$ cells resulted in a 2-fold increase in the percentage of $\mathrm{ALDH}^{+}$cells undergoing asymmetric division (Fig. 3Cii). This was associated with a statistically significant increase in total cell numbers: 6.5 vs. 3.7 average cells/well and a total of 325 vs. 185 daughter cells generated for every 50 captured cells in EGFL6-treated $\mathrm{ALDH}^{+}$vs. control $\mathrm{ALDH}^{+}$cells, respectively. EGFL6 treatment of $\mathrm{ALDH}^{(-)} \mathrm{SKOV} 3$ cells had no significant impact on proliferation rates.

We confirmed these results with cells from three separate primary ovarian cancer debulking specimens. Primary cells divided more slowly thus division was assessed after 96 hours of EGFL6 treatment. For primary cells, we observed that over 50\% of untreated $\mathrm{ALDH}^{(-)}$cells underwent no division (Fig. 3Ciii). $\mathrm{ALDH}^{(-)}$cells which underwent cell division generated only $\mathrm{ALDH}^{(-)}$progeny. EGFL6 treatment of $\mathrm{ALDH}^{(-)}$cells was associated with a nonstatistically significant $(\mathrm{p}=0.15)$ increase in average number of progeny/well and total cell numbers (Fig. 3Ciii). As in cell lines, primary $\mathrm{ALDH}^{+}$cells were more proliferative than $\mathrm{ALDH}^{(-)}$cells with only $20 \%$ of $\mathrm{ALDH}^{+}$cells not dividing (Fig. 3Ciii). EGFL6 treatment resulted in an increase in number of progeny cells per well and total cell numbers (Fig. 3Ciii). Likely due to the slower growth of primary cells, this did not reach statistical significance $(\mathrm{p}=0.09)$. EGFL6 treatment of primary $\mathrm{ALDH}^{+}$cells was associated with a statistically significant $(\mathrm{p}=0.02)$ 1.9-fold increase in the number of $\mathrm{ALDH}^{+}$cells undergoing asymmetric division (Fig. 3Ciii).

\section{EGFL6 Signaling Involves Integrin binding and SHP2 activation}

EGFL6 activity is reported to be dependent on an intact RGD domain (16), suggesting signaling via integrins. To determine if EGFL6 signals via integrins in cancer cells, we generated an EGFL6 protein with an RGD-to-RGE mutation (EGFL6 ${ }^{\mathrm{RGE}}$ ). Mutation of the RGD domain eliminated the proliferative effects of EGFL6 (Fig. 4A).

To identify integrin family members involved in EGFL6 signaling, we performed qRT-PCR analysis of integrin family mRNA expression in $\mathrm{ALDH}^{+}$and $\mathrm{ALDH}^{(-)}$ovarian cancer cells. 
We found that Integrin $\beta_{3}$ (ITGB3), but not Integrin $\beta 1$ or $\beta_{5}$, was specifically enriched in ALDH $^{+}$SKOV3 and A2008 cells (Fig. 4B). We tested the impact of the Integrin $\beta 1 / \beta 3$ inhibitor Echistatin on ovarian cancer cell response to EGFL6. Echistatin blocked both EGFL6-mediated cancer cell proliferation and the decrease in $\mathrm{ALDH}^{+}$percentage (Fig. 4C). Interestingly, Integrin $\beta_{3}$-blocking antibody independently restricted ovarian cancer cell growth but only partially prevented EGFL6-induced proliferation (Supplemental Fig. 2A). Finally, we performed co-immunoprecipitation studies of EGFL6, EGFL6 ${ }^{\mathrm{RGE}}$, and Integrin$\beta 3$. Wild-type EGFL6 co-immunoprecipitated with Integrin- $\beta 3$ 4.6-fold more effectively than EGFL6 ${ }^{\mathrm{RGE}}$. Interestingly, mixing wild-type EGFL6 with EGFL6 ${ }^{\mathrm{RGE}}$ also compromised EGFL6 binding to Integrin $\beta 3$ (Supplemental Fig. 2B).

We next examined cellular signaling changes associated with EGFL6 treatment. Western blot analysis of $\mathrm{ALDH}^{+}$and $\mathrm{ALDH}^{(-)}$SKOV3 cells demonstrated 2.4-fold increased levels of pSHP2 in $\mathrm{ALDH}^{+}$cells vs. ALDH ${ }^{(-)}$cells (Fig. 4Di). EGFL6 treatment resulted in an additional 2-fold increase in pSHP2 levels specifically in $\mathrm{ALDH}^{+}$cells (Fig. 4Di). EGFL6 treatment also resulted in a 4-fold increase in p-ERK levels in $\mathrm{ALDH}^{+}$cells, and a 1.8-fold increase in p-ERK in $\mathrm{ALDH}^{(-)}$cells (Fig. 4Di). EGFL6 ${ }^{\mathrm{RGE}}$ did not increase pSHP2 (Fig. 4Dii) or p-ERK, although effects on p-ERK were more variable. EGFL6-mediated phosphorylation of SHP2 and ERK could be blocked by Echistatin or EGFL6-blocking antibodies (Fig. 4Diii- see below for EGFL6-blocking antibody validation). Integrin $\beta 3$ blocking antibodies blocked EGFL6-mediated increases in pSHP2, but only partly abrogated the increase in p-ERK (Supplemental Fig. 2C).

Direct interactions of SHP2 with Integrin protein complexes have been reported (27). Immunoprecipitation of either integrin $\beta 3$ or SHP2 confirmed interactions of the two proteins in ovarian cancer cells (Supplemental Fig. 2D). Confirming a critical role for SHP2 in EGFL6 signaling on ovarian CSC, shRNA knockdown of SHP2 with three independent SHP2 shRNA (Fig. 4Ei) was associated with a significant decrease in $\mathrm{ALDH}^{+}$cells in all cases (Fig. 4Eii; Supplemental Fig. 3A). This is analogous to that seen in breast cancer (28). SHP2 knockdown was associated with a significant decrease in total cell numbers (Fig. 4Eiii), and a 5-8.5 fold decrease in the absolute number of $\mathrm{ALDH}^{+}$cells (Fig. 4E). SHP2 knockdown eliminated EGFL6-mediated tumor cell proliferation (Fig. 4Eiii). Similarly, treatment of ovarian cancer cell lines with the SHP2 inhibitor 11a-1 (19) resulted in a dosedependent reduction in the total cell number, and percentage and absolute number of $\mathrm{ALDH}^{+}$cells (Fig. 4Fi-ii; Supplemental Fig. 3B). Increasing doses of 11a-1 were associated with an increase in cell death, though the quantity of cell deaths might not completely explain the significant reduction in total cell numbers (Supplemental Fig. 3Bii).

\section{EGFL6 expression by tumor cells increases tumor growth in vivo}

We next assessed in vivo tumor-growth effect of EGFL6 expression by tumor cells. As SKOV3 cells do not express EGFL6, we evaluated the growth of two stably transfected EGFL6-expressing SKOV3 clones. Both clones demonstrated increased growth rates relative to vector-only transfected control cell clones (Fig. 5Ai; Supplemental Fig. 4Ai-ii). EGFL6expressing tumors demonstrated an increase in percentage of Ki67-expressing cells and a decrease in the concentration of $\mathrm{ALDH}^{+}$cells (Fig. 5Aii; Supplemental Fig. 4Aiii). Given 
the increased tumor volume, there was no estimated change in absolute number of $\mathrm{ALDH}^{+}$ cells. Similarly, SKOV3 cells transduced with lentivirus EGFL6-GFP, compared to GFPonly controls, demonstrated increased tumor growth based on both tumor weight and GFP intensity (Supplemental Fig. 4B).

We next evaluated the impact of EGFL6 knockdown on the growth of NIHOVCAR3 HGSC cells, which express high levels of EGFL6. We validated EGFL6 knockdown with three EGFL6 shRNAs (Fig. 5Bi). EGFL6 knockdown was associated with a significant reduction in pSHP2 for all shRNAs (Fig. 5Biii) and, for two of three shRNAs, EGFL6 knockdown was associated with a reduction in total SHP2 levels (Fig. 5Biii). Analogous to SHP2 knockdown, EGFL6 knockdown resulted in a significant 2.4-fold reduction in $\mathrm{ALDH}^{+}$cells (Fig. 5Bii; Supplemental Fig. 5). EGFL6 knockdown was associated with significantly reduced tumor growth in vivo, an almost 2-fold increase in animal survival, and a 1.9-fold reduction in $\mathrm{ALDH}^{+}$cells (Fig. 5Biv-vi).

To further test the role of EGFL6 in vivo, we developed an EGFL6-blocking antibody (antiEGFL6) which blocked EGFL6-triggered (i) increases in cell proliferation, (ii) changes in $\mathrm{ALDH}^{+}$cell percentages, and (iii) increases in p-SHP2 and p-ERK (Fig. 4Diii;

Supplemental Fig. 6). While this antibody was non-reactive on western blot, the antibody detected EGFL6 via immunofluorescence and was able to immunoprecipitate EGFL6 in transduced cells (Supplemental Fig. 6). Anti-EGFL6 treatment of mice bearing NIHOVCAR3 flank tumors were resulted in a significant reduction of tumor growth ( $\mathrm{p}<0.0001$, Fig. 5Ci-ii), a 35\% reduction in the percentage of $\mathrm{ALDH}^{+}$cells, and a 7-fold reduction in absolute $\mathrm{ALDH}^{+}$cell number (Fig. 5Ciii-iv).

\section{Vascular EGFL6 promotes tumor growth and metastasis in vivo}

We next investigated the impact of vascular EGFL6 expression on ovarian tumor growth. To do this, we used human hemangioma stem cells (HemSC) to create human tumor blood vessels expressing EGFL6. HemSC have been shown to proliferate and generate blood-filled human vessels in vivo in mice $(29,30)$. HemSC have low/no expression of EGFL6 at baseline (Fig.1D). We transduced HemSC with EGFL6 lentivirus and confirmed strong EGFL6 expression (Fig. 6A). When SKOV3 cells and HemSC ${ }^{\text {EGFL6 }}$ cells were co-injected in vivo, we observed robust human $\mathrm{CD} 31^{+}$tumor vessels which expressed EGFL6 (Fig. 6B). SKOV3 cells grown with HemSC ${ }^{\text {EGFL6 }}$ cells demonstrated increased growth compared to SKOV3 cells grown with HemSC ${ }^{\text {Control }}$ (Fig. 6C). As observed with EGFL6 expression in tumor cells, expression of EGFL6 by HemSC cells was associated with increased numbers of $\mathrm{Ki}^{+}$cells (Fig. 6D). Confirming growth was related to EGFL6, treatment of SKOV3:HemSC EGFL6 tumors with anti-EGFL6 abrogated EGFL6-stimulated tumor growth (Supplemental Fig. 7).

This experiment was then repeated with primary cells from four different patients $(\mathrm{n}=2$ tumors each). We observed tumor initiation in 8 of 8 primary tumors co-injected with HemSC ${ }^{\text {EGFL6 }}$ compared to 3 of 8 tumor samples co-injected with HemSC ${ }^{\text {Control }}$. As in cell lines, EGFL6 expression by HemSC cells was associated with more rapid tumor growth and increased Ki67 stain (Fig. 6E and F). 
Mice treated with anti-EGFL6 lost hair. Given EGFL6 is known to be expressed in the hair follicle (14), this is presumably an on-target side effect suggesting anti-EGFL6 could target murine EGFL6. We thus tested whether anti-EGFL6 treatment could inhibit the growth of non-EGFL6-expressing SKOV3 tumors. While anti-EGFL6 did not impact the growth of SKOV3 cells grown in vitro, twice weekly intraperitoneal treatment with anti-EGFL6 treatment of SKOV3 flank tumors resulted in a $~ 2$-fold reduction of in vivo SKOV3 tumor growth (Fig. 6Gi-ii). Analysis of tumors indicated a 3.2-fold reduction in the percentage of $\mathrm{ALDH}^{+}$cells and a 9-fold reduction in absolute $\mathrm{ALDH}^{+}$cell number (Fig. 6Giii-iv).

Integrin and SHP2 signaling have been linked with metastatic capacity in several tumor types. Suggesting EGFL6 could play a role in metastasis, GSEA analysis revealed that EGFL6 expression correlated with the expression of multiple metastasis-related gene sets (Fig. 7A and Supplemental Fig. 1C). We therefore evaluated the ability of EGFL6 to act as a chemotropic factor. We used a microfluidic channel (22) to create a gradient of EGFL6 and evaluated the migration of $\mathrm{ALDH}^{+}$and $\mathrm{ALDH}^{(-)}$ovarian cancer cells towards EGFL6containing media. While EGFL6 had no impact on $\mathrm{ALDH}^{(-)}$cells, $\mathrm{ALDH}^{+}$cells demonstrated statistically significant migration towards EGFL6-containing media (Fig. 7B). Similarly, EGFL6 treatment was associated with increased 'wound healing' in a standard scratch assay (Supplemental Fig. 8).

To evaluate the impact of EGFL6 on metastasis in vivo, we first evaluated mice bearing EGFL6-expressing flank tumors. When tumor cells expressed EGFL6 (from experiment in Fig. 5A; Supplemental Fig. 4) we observed no metastases from flank tumors either grossly or via luciferase imaging. Similarly, when SKOV3 cells were grown with HemSC Control cells in vivo, we observed no metastasis. In contrast, when SKOV3 cells were grown with HemSC ${ }^{\text {EGFL6 }}$, we observed metastases in 4/10 mice (Fig. 7Ci-metastases were observed in the liver, lung, and ovary with associated ascites). Lymphovascular space invasion of $\mathrm{ALDH}^{+}$cells was detected in HemSC ${ }^{\text {EGFL6 }}$ flank tumors (Fig. 7Cii). We similarly evaluated metastases from primary ovarian cells grown with HemSC ${ }^{\text {Control }}$ or HemSC ${ }^{\text {EGFL6 }}$. In the presence of $\mathrm{HemSC}^{\mathrm{Control}}$, we observed pulmonary metastases in $1 / 3$ mice which generated tumors, whereas with HemSC ${ }^{\text {EGFL6 }}$ we observed metastases in 2/4 mice with metastases in the lungs, liver, and to the ovary (Fig. 7D).

We next assessed the ability of anti-EGFL6 to inhibit ovarian cancer metastasis. We performed IP injections of ovarian cancer cells and evaluated the impact of anti-EGFL6. Anti-EGFL6 led to a 3-fold reduction in the average number of tumor nodules (Fig. 7D). Furthermore, while control animals had tumor nodules in the ovary and liver, anti-EGFL6treated animals had disease limited to the bowel/omentum with no detectable ovarian tumors on/in the liver or ovaries.

We have recently shown that ovarian cancer cells injected intravenously preferentially metastasize to the ovary (31). EGFL6 is expressed in the ovary. We assessed if EGFL6 could recruit ovarian cancer cells to the ovary. Mice were treated with anti-EGFL6 for 3 days and then injected with SKOV3 cells intravenously via the tail vein. Anti-EGFL6 therapy was continued for an additional 2 weeks. As expected, control mice developed metastases in not only the liver and lung but also in the ovaries, and in the peritoneal cavity with the 
development of ascites. While treatment with anti-EGFL6 had no impact on lung metastases, it reduced liver nodules 6-fold and completely eliminated ovarian metastases and ascites (Fig. 7E). Together, these data suggest that EGFL6 plays a role in ovarian cancer metastasis and that anti-EGFL6 therapy might restrict the spread of ovarian cancer.

\section{Discussion}

Vascular endothelial cells are regulators of the stem cell niche (6,32). Given the proximity of CSC and endothelial cells, a parallel role for endothelial cells and CSC has been proposed. Endothelial cells have been suggested to directly provide "angiocrine" factors that direct stem cell fate $(33,34)$. EGFL6 represents one such angiocrine factor. Consistent with a role for EGFL6 as an angiocrine factor in ovarian cancer, it is reported to be present in the serum of patients with ovarian cancer at levels 200-300X higher than that of healthy controls (35).

We found EGFL6 promotes tumorigenesis by inducing $\mathrm{ALDH}^{+}$cells to undergo asymmetric division. This results in $\mathrm{ALDH}^{+}$cell maintenance, the production of $\mathrm{ALDH}^{(-)}$cells, and an increase in tumor growth. Supporting a role of EGFL6 in asymmetric division, acute EGFL6 exposure is associated with a decrease in $\mathrm{ALDH}^{+}$cell percentage, but no change in the absolute $\mathrm{ALDH}^{+}$cell number. Similarly, short-term EGFL6 blockade increases ALDH ${ }^{+}$cell percentage without changing absolute cell number. In contrast, EGFL6 knockdown or longterm blockade was associated with a significant reduction in both the percentage and absolute number of $\mathrm{ALDH}^{+}$cells. This suggests that EGFL6, either related to or independent of the ability to promote asymmetric division, might play a role in $\mathrm{ALDH}^{+}$cell maintenance. This would be consistent with EGFL6 signaling via SHP2, which plays a role in breast cancer stem cell maintenance (28). Interestingly, SHP2 signals in conjunction with the adaptor protein GAB2 $(36,37)$. Consistent with a critical role for SHP2 in ovarian cancer, GAB2 was recently reported to be an oncogene in ovarian cancer (38). Parallel to our studies with EGFL6, GAB2 expression was associated with increased activation of ERK. Additional studies will be necessary to determine whether EGFL6 signals via GAB2. However, our work supports EGFL6 as a therapeutic target in ovarian cancer.

EGFL6 is expressed in both cancer cells and vascular cells. To study the role of human EGFL6 in a human vascular niche, we developed a new model of human tumor vasculature using HemSC. When combined with human ovarian tumor cells, the HemSC contributed to the tumor vasculature by creating human tumor vessels which were viable for as long as tumors were maintained. Using the HemSC-derived tumor model, we observed that vascular EGFL6 expression, similar to tumor cell EGFL6 expression, promoted the growth of tumor xenografts. In addition, vascular EGFL6 expression was associated with an increase in metastases for both cell lines and primary cancer cells. This is consistent with recent studies which not only demonstrated a role of hematogenous metastasis for ovarian cancer, but also identified upregulation of EGFL6 with hematogenous ovarian cancer metastases (39). Interestingly, a predominant site of metastasis was the ovary, which also expresses EGFL6. Anti-EGFL6 demonstrated an ability to completely eliminate hematogenous spread of ovarian cancer cells to the ovary, suggesting that EGFL6 might play a critical role in the ovarian microenvironment. Consistent with this, EGFL6 exon-1 knockout mice are prenatal 
lethal specifically in female mice (MMRRC). Inducible EGFL6 knockout mice will need to be developed to further explore the role of EGFL6 in ovarian cancer.

Our data strongly support EGFL6 as a therapeutic target in ovarian cancer. EGFL6 blockade/ knockdown strongly suppressed tumor growth and reduced metastasis. mRNA microarray expression data suggest that EGFL6 is also expressed at very high levels in uterine tumors and aerodigestive tumors $(11,35)$. EGFL6 is elevated in the serum of patients with glioblastoma, bladder, breast, gastric, liver, lung, pancreatic, and prostate cancers (35). Thus, EGFL6 could be an important target for other tumor types.

In conclusion, EGFL6 is an angiocrine and tumor cell factor which promotes tumorigenesis via SHP2-mediated signaling. EGFL6 stimulates $\mathrm{ALDH}^{+}$ovarian CSC to migrate and undergo asymmetric division. As such, EGFL6 specifically promotes ovarian cancer cell metastasis. Finally, a novel EGFL6-blocking antibody abrogated the impact of EGFL6 on ovarian tumor growth and metastasis, suggesting this antibody represents a novel therapeutic.

\section{Supplementary Material}

Refer to Web version on PubMed Central for supplementary material.

\section{Acknowledgments}

Financial Support: This work was supported by the OCRFA and the DOD-OCRP Idea Award W81XWH-14-1-0187. UMCC core facilities were supported by the NIH Support Grant (P30 CA046592).

We thank David Cheresh for providing the Integrin $\beta 3$-blocking antibody.

\section{References}

1. Choi Y-J, Ingram PN, Yang K, Coffman L, Iyengar M, Bai S, et al. Identifying an ovarian cancer cell hierarchy regulated by bone morphogenetic protein 2. Proceedings of the National Academy of Sciences. 2015; 112(50):E6882-E6888.

2. Silva IA, Bai S, McLean K, Yang K, Griffith K, Thomas D, et al. Aldehyde dehydrogenase in combination with CD133 defines angiogenic ovarian cancer stem cells that portend poor patient survival. Cancer Res. 2011; 71(11):3991-4001. [PubMed: 21498635]

3. Steg AD, Bevis KS, Katre AA, Ziebarth A, Dobbin ZC, Alvarez RD, et al. Stem Cell Pathways Contribute to Clinical Chemoresistance in Ovarian Cancer. Clinical cancer research : an official journal of the American Association for Cancer Research. 2012; 18(3):869-881. [PubMed: 22142828]

4. Landen CN Jr, Goodman B, Katre AA, Steg AD, Nick AM, Stone RL, et al. Targeting aldehyde dehydrogenase cancer stem cells in ovarian cancer. Mol Cancer Ther. 2010; 9(12):3186-3199. [PubMed: 20889728]

5. Charafe-Jauffret E, Ginestier C, Iovino F, Tarpin C, Diebel M, Esterni B, et al. Aldehyde dehydrogenase 1-positive cancer stem cells mediate metastasis and poor clinical outcome in inflammatory breast cancer. Clinical cancer research : an official journal of the American Association for Cancer Research. 2010; 16(1):45-55. [PubMed: 20028757]

6. Shen Q, Goderie SK, Jin L, Karanth N, Sun Y, Abramova N, et al. Endothelial cells stimulate selfrenewal and expand neurogenesis of neural stem cells. Science. 2004; 304(5675):1338-1340. [see comment]. [PubMed: 15060285] 
7. Holmberg J, Genander M, Halford MM, Anneren C, Sondell M, Chumley MJ, et al. EphB receptors coordinate migration and proliferation in the intestinal stem cell niche. Cell. 2006; 125(6):11511163. [PubMed: 16777604]

8. Calabrese C, Poppleton H, Kocak M, Hogg TL, Fuller C, Hamner B, et al. A perivascular niche for brain tumor stem cells. Cancer cell. 2007; 11(1):69-82. [PubMed: 17222791]

9. Gilbertson RJ, Rich JN. Making a tumour's bed: glioblastoma stem cells and the vascular niche. Nature Reviews Cancer. 2007; 7(10):733-736. [PubMed: 17882276]

10. Butler JM, Kobayashi H, Rafii S. Instructive role of the vascular niche in promoting tumour growth and tissue repair by angiocrine factors. Nature reviews Cancer. 2010; 10(2):138-146.

11. Buckanovich RJ, Sasaroli D, O'Brien-Jenkins A, Botbyl J, Hammond R, Katsaros D, et al. Tumor vascular proteins as biomarkers in ovarian cancer. J Clin Oncol. 2007; 25(7):852-861. [PubMed: 17327606]

12. Lu C, Bonome T, Li Y, Kamat AA, Han LY, Schmandt R, et al. Gene alterations identified by expression profiling in tumor-associated endothelial cells from invasive ovarian carcinoma. Cancer Res. 2007; 67(4):1757-1768. [PubMed: 17308118]

13. Yeung G, Mulero JJ, Berntsen RP, Loeb DB, Drmanac R, Ford JE. Cloning of a novel epidermal growth factor repeat containing gene EGFL6: expressed in tumor and fetal tissues. Genomics. 1999; 62(2):304-307. [PubMed: 10610727]

14. Osada A, Kiyozumi D, Tsutsui K, Ono Y, Weber CN, Sugimoto N, et al. Expression of MAEG, a novel basement membrane protein, in mouse hair follicle morphogenesis. Experimental cell research. 2005; 303(1):148-159. [PubMed: 15572035]

15. Fujiwara H, Ferreira M, Donati G, Marciano DK, Linton JM, Sato Y, et al. The basement membrane of hair follicle stem cells is a muscle cell niche. Cell. 2011; 144(4):577-589. [PubMed: 21335239]

16. Chim SM, Qin A, Tickner J, Pavlos N, Davey T, Wang H, et al. EGFL6 promotes endothelial cell migration and angiogenesis through the activation of extracellular signal-regulated kinase. J Biol Chem. 2011; 286(25):22035-22046. [PubMed: 21531721]

17. Oberauer R, Rist W, Lenter MC, Hamilton BS, Neubauer H. EGFL6 is increasingly expressed in human obesity and promotes proliferation of adipose tissue-derived stromal vascular cells. Mol Cell Biochem. 2010; 343(1-2):257-269. [PubMed: 20574786]

18. Pulaski HL, Spahlinger G, Silva IA, McLean K, Kueck AS, Reynolds RK, et al. Identifying alemtuzumab as an anti-myeloid cell antiangiogenic therapy for the treatment of ovarian cancer. $\mathbf{J}$ Transl Med. 2009; 7:49. [PubMed: 19545375]

19. Zeng LF, Zhang RY, Yu ZH, Li S, Wu L, Gunawan AM, et al. Therapeutic potential of targeting the oncogenic SHP2 phosphatase. Journal of medicinal chemistry. 2014; 57(15):6594-6609. [PubMed: 25003231]

20. Rhodes DR, Kalyana-Sundaram S, Mahavisno V, Varambally R, Yu J, Briggs BB, et al. Oncomine 3.0: genes, pathways, and networks in a collection of 18,000 cancer gene expression profiles. Neoplasia. 2007; 9(2):166-180. [PubMed: 17356713]

21. Choi Y, Ingram PN, Yang K, Coffman Y, Iyengar M, Bai S, et al. Identifying an Ovarian Cancer Hierarchy Regulated by BMP2. PNAS. 2015 in press.

22. Chen YC, Allen SG, Ingram PN, Buckanovich R, Merajver SD, Yoon E. Single-cell Migration Chip for Chemotaxis-based Microfluidic Selection of Heterogeneous Cell Populations. Scientific reports. 2015; 5:9980. [PubMed: 25984707]

23. McLean K, Gong Y, Choi Y, Deng N, Yang K, Bai S, et al. Human ovarian carcinoma-associated mesenchymal stem cells regulate cancer stem cells and tumorigenesis via altered BMP production. J Clin Invest. 2011; 121(8):3206-3219. [PubMed: 21737876]

24. Kryczek I, Liu S, Roh M, Vatan L, Szeliga W, Wei S, et al. Expression of aldehyde dehydrogenase and CD133 defines ovarian cancer stem cells. Int J Cancer. 2012; 130(1):29-39. [PubMed: 21480217]

25. Deng S, Yang X, Lassus H, Liang S, Kaur S, Ye Q, et al. Distinct expression levels and patterns of stem cell marker, aldehyde dehydrogenase isoform 1 (ALDH1), in human epithelial cancers. PloS one. 2010; 5(4):e10277. [PubMed: 20422001] 
26. Chung J, Kim YJ, Yoon E. Highly-efficient single-cell capture in microfluidic array chips using differential hydrodynamic guiding structures. Appl Phys Lett. 2011; 98(12):123701. [PubMed: 21673831]

27. Lacalle RA, Mira E, Gomez-Mouton C, Jimenez-Baranda S, Martinez AC, Manes S. Specific SHP-2 partitioning in raft domains triggers integrin-mediated signaling via Rho activation. The Journal of cell biology. 2002; 157(2):277-289. [PubMed: 11956229]

28. Aceto N, Sausgruber N, Brinkhaus H, Gaidatzis D, Martiny-Baron G, Mazzarol G, et al. Tyrosine phosphatase SHP2 promotes breast cancer progression and maintains tumor-initiating cells via activation of key transcription factors and a positive feedback signaling loop. Nat Med. 2012; 18(4):529-537. [PubMed: 22388088]

29. Boscolo E, Bischoff J. Vasculogenesis in infantile hemangioma. Angiogenesis. 2009; 12(2):197207. [PubMed: 19430954]

30. Khan ZA, Melero-Martin JM, Wu X, Paruchuri S, Boscolo E, Mulliken JB, et al. Endothelial progenitor cells from infantile hemangioma and umbilical cord blood display unique cellular responses to endostatin. Blood. 2006; 108(3):915-921. [PubMed: 16861344]

31. Coffman LG, Burgos-Ojeda D, Bai S, Buckanovich RJ. Murine ovarian cancer metastasis models demonstrate preferential spread of ovarian cancer cells to the ovary. Translational Research. 2016 in second review:pii: S1931-5244(16)00108-0.

32. Cleaver O, Dor Y. Vascular instruction of pancreas development. Development. 2012; 139(16): 2833-2843. [PubMed: 22833471]

33. Bergers G, Hanahan D. Modes of resistance to anti-angiogenic therapy. Nature reviews Cancer. 2008; 8(8):592-603. [PubMed: 18650835]

34. Hanahan D, Weinberg RA. Hallmarks of cancer: the next generation. Cell. 2011; 144(5):646-674. [PubMed: 21376230]

35. Wang X, Gong Y, Wang D, Xie Q, Zheng M, Zhou Y, et al. Analysis of Gene Expression Profiling in Meningioma: Deregulated Signaling Pathways Associated with Meningioma and EGFL6 Overexpression in Benign Meningioma Tissue and Serum. PloS one. 2012; 7(12):e52707. [PubMed: 23285163]

36. Futami M, Zhu QS, Whichard ZL, Xia L, Ke YH, Neel BG, et al. G-CSF receptor activation of the Src kinase Lyn is mediated by Gab2 recruitment of the Shp2 phosphatase. Blood. 2011; 118(4): 1077-1086. [PubMed: 21636860]

37. Gu H, Pratt JC, Burakoff SJ, Neel BG. Cloning of p97/Gab2, the Major SHP2-Binding Protein in Hematopoietic Cells, Reveals a Novel Pathway for Cytokine-Induced Gene Activation. Mol Cell. 1998; 2(6):729-740. [PubMed: 9885561]

38. Dunn GP, Cheung HW, Agarwalla PK, Thomas S, Zektser Y, Karst AM, et al. In vivo multiplexed interrogation of amplified genes identifies GAB2 as an ovarian cancer oncogene. Proceedings of the National Academy of Sciences of the United States of America. 2014; 111(3):1102-1107. [PubMed: 24385586]

39. Pradeep S, Kim SW, Wu SY, Nishimura M, Chaluvally-Raghavan P, Miyake T, et al. Hematogenous metastasis of ovarian cancer: rethinking mode of spread. Cancer cell. 2014; 26(1): 77-91. [PubMed: 25026212] 

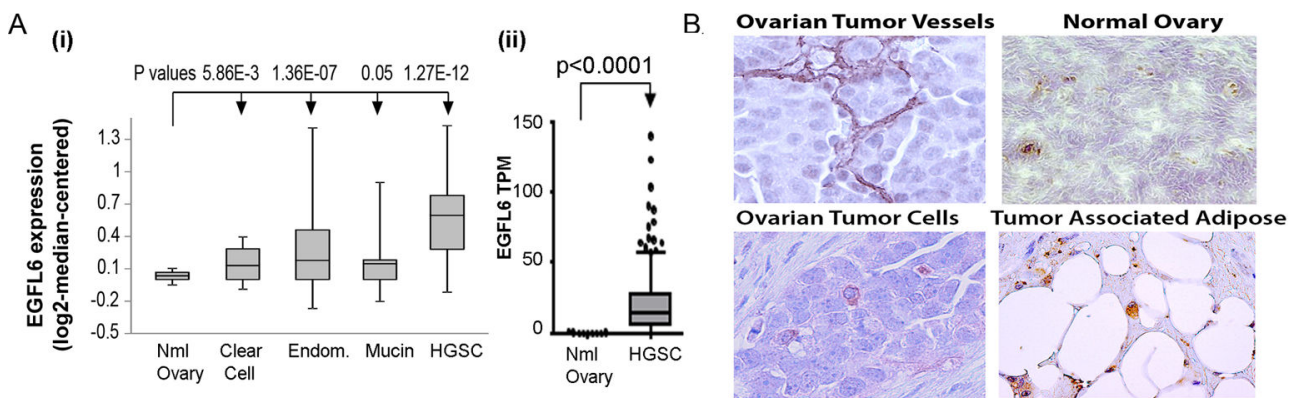

C

\section{EGFL6}
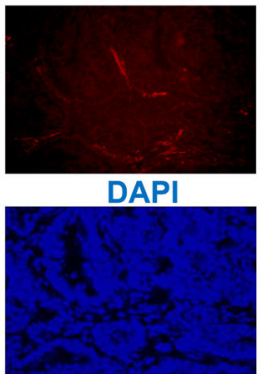

E

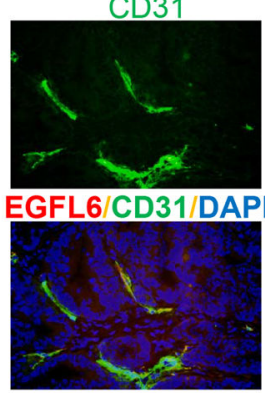

-2. EGFL6 Low - EGFL6 High

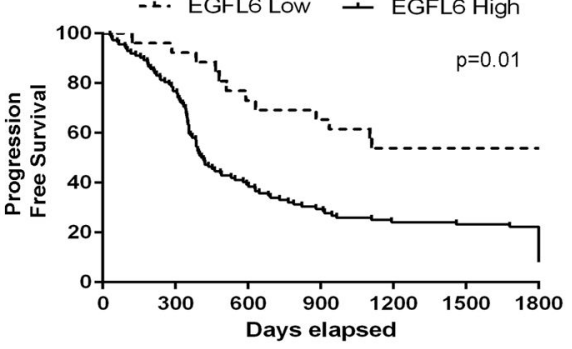

F

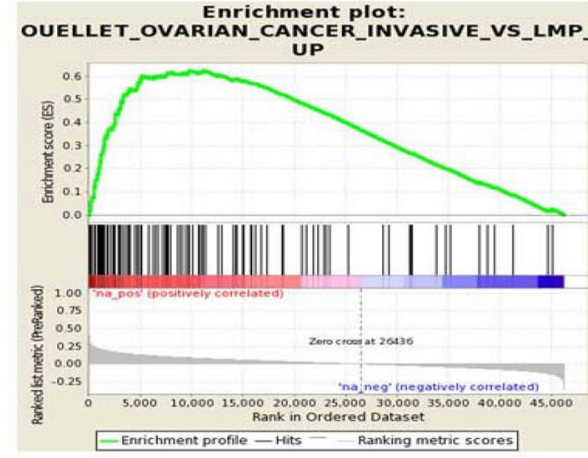

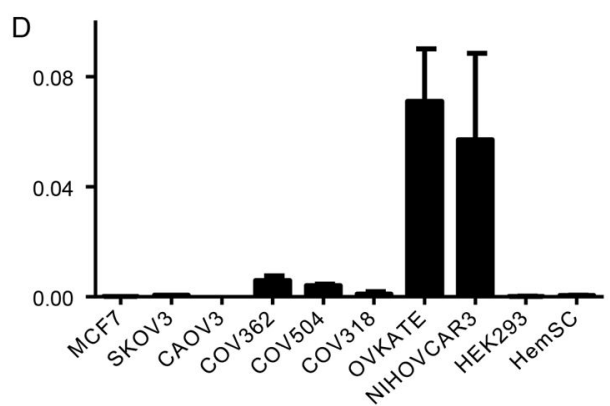
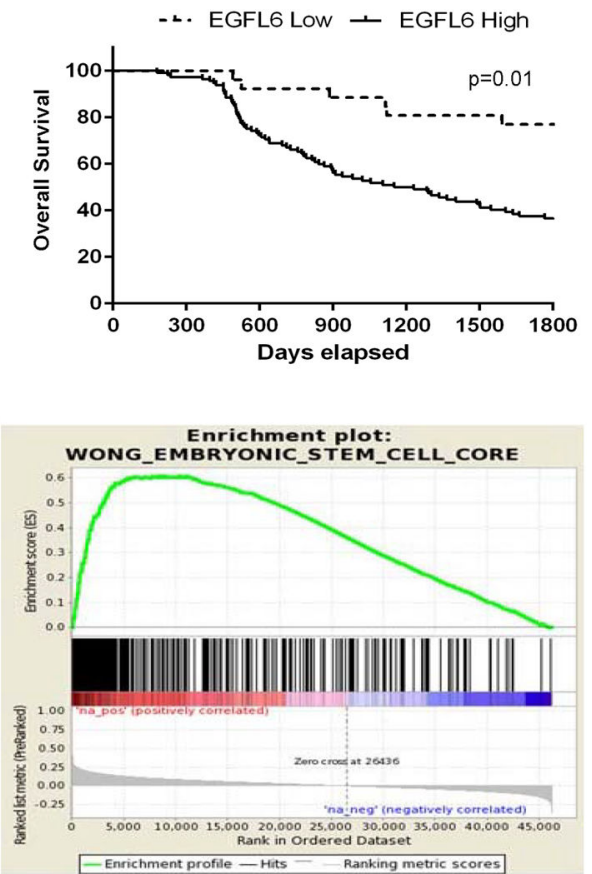

Figure 1. Expression of EGFL6 in ovarian tumors and normal tissue

A. Expression of EGFL6 across ovarian cancers histologies in the (i) Hendrix dataset (ii) TCGA, GTEx datasets. B. IHC of EGFL6 in the indicated tissues. C. Immunofluorescence of EGFL6 (red) and CD31 (green) in human tumor vasculature (blue is DAPI staining of nucleus). D. qRT-PCR analysis of EGFL6 expression in ovarian cancer cell lines, MCF7 (breast cancer), HEK293 (kidney), and hemangioma stem cells (HemSC) controls. E. Kaplan Meier curves for recurrence-free and overall survival for ovarian cancer patients with or without vascular EGFL6 expression in primary debulking specimens. F. GSEA 
demonstrating EGFL6-correlated genes are associated with invasive ovarian cancer phenotype and an Embryonic Stem Cell core signature. See Suppl.Fig1C for ES scores, pvalues, and FDR q-values. 


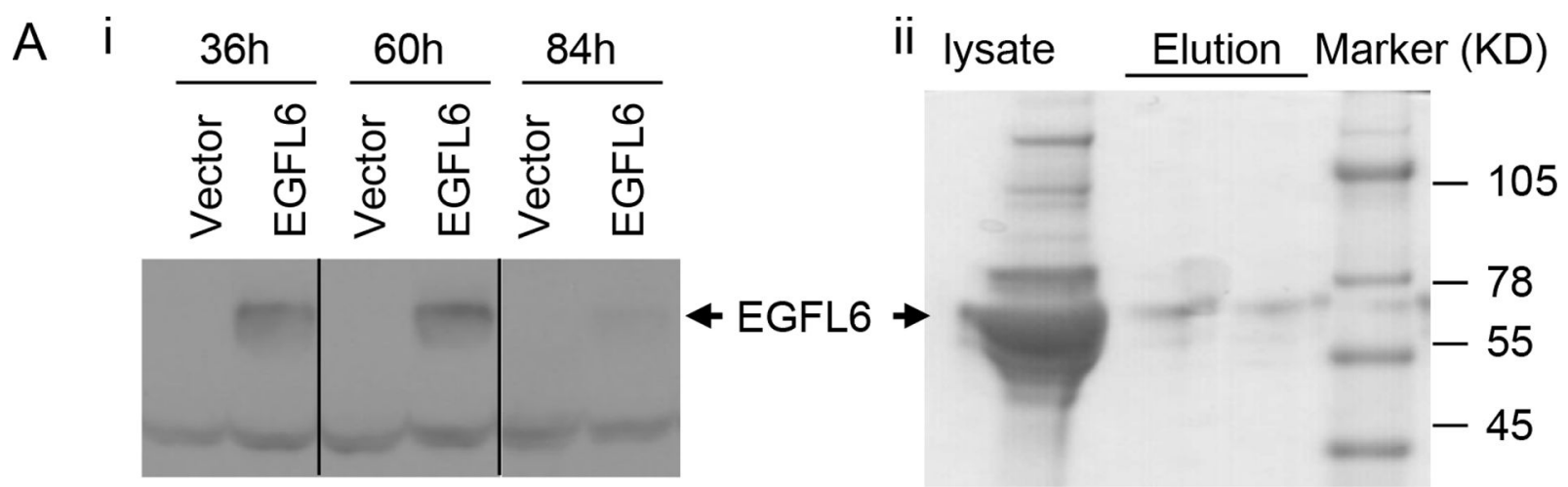

B

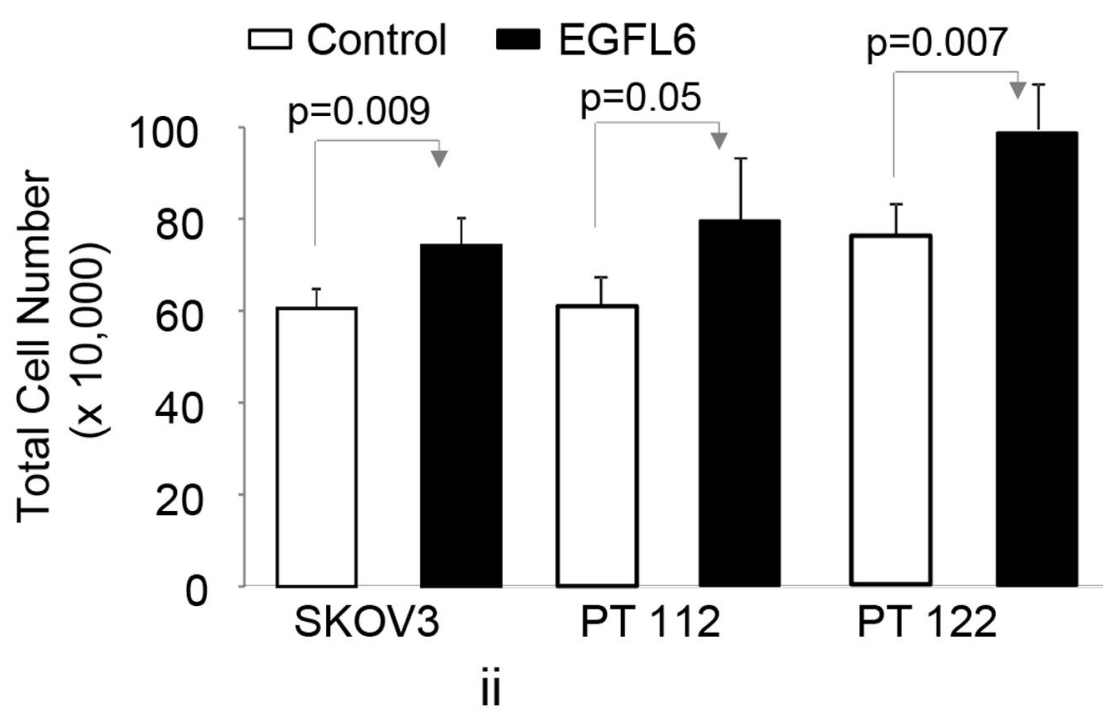

C i

$\square$ G1 $\because \mathrm{S} \quad \mathbf{D G} 2 / \mathrm{M}$
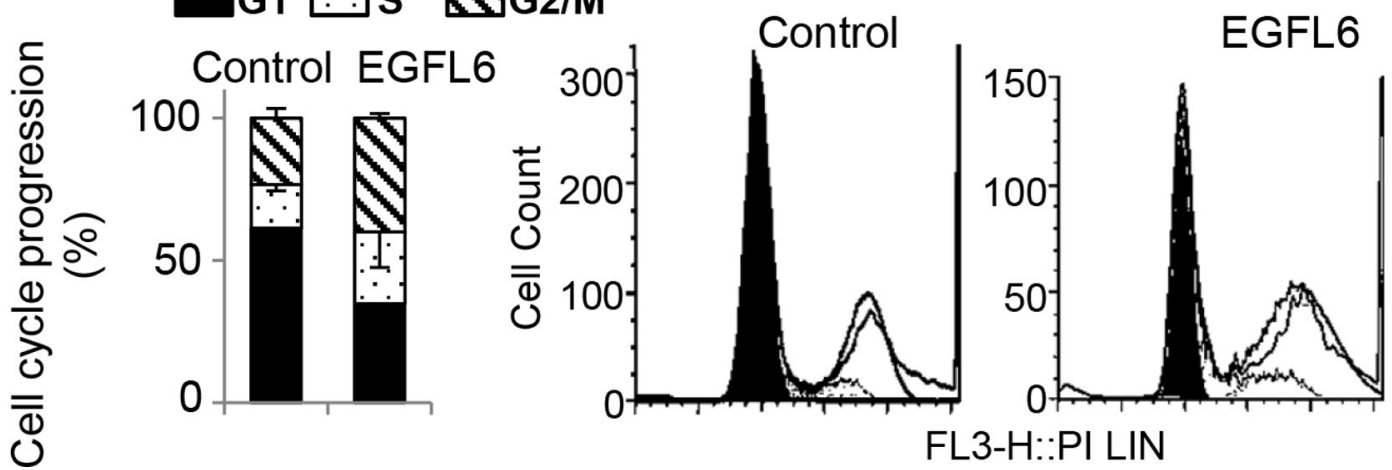

FL3-H::PI LIN

Figure 2. Effect of EGFL6 on ovarian cancer cell proliferation

A(i). Western blot of EGFL6 following control or EGFL6 transfection of HEK293 cells, (ii)

Coomassie stain of the steps of EGFL6 purification. B. Total cell number for EGFL6 and vehicle control-treated SKOV3 cells and primary tumor cells (PT112 and PT122). C. Cellcycle analysis of EGFL6-treated SKOV3 cells showing, (i) Summary of 3 independent analyses and, (ii) Representative cell cycle profile. Experiments were performed in duplicate. Error bars represent standard deviations. 
A

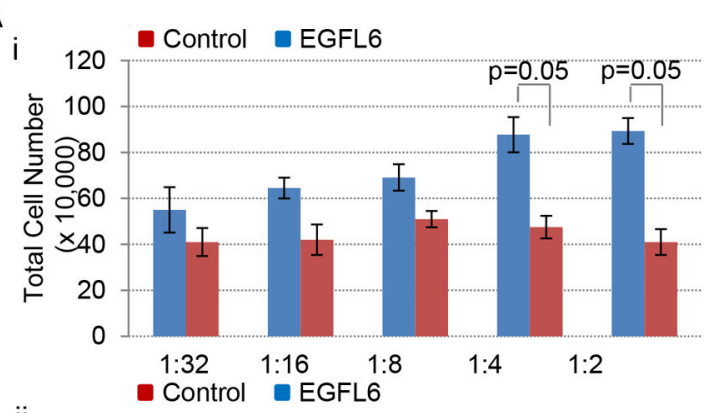

ii

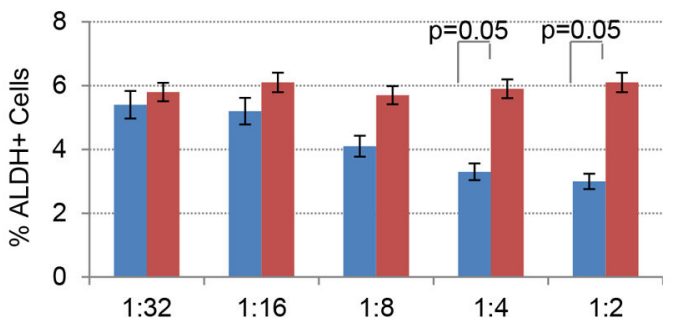

iii

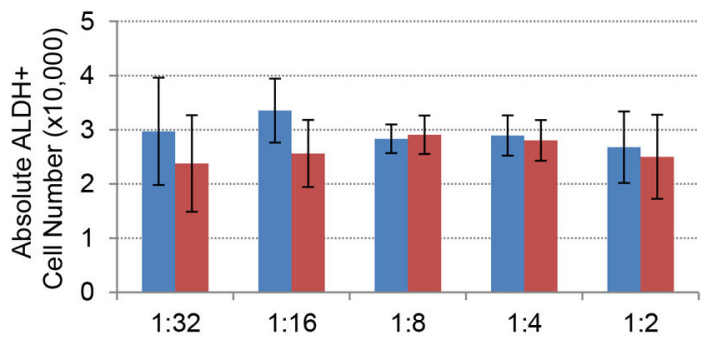

B

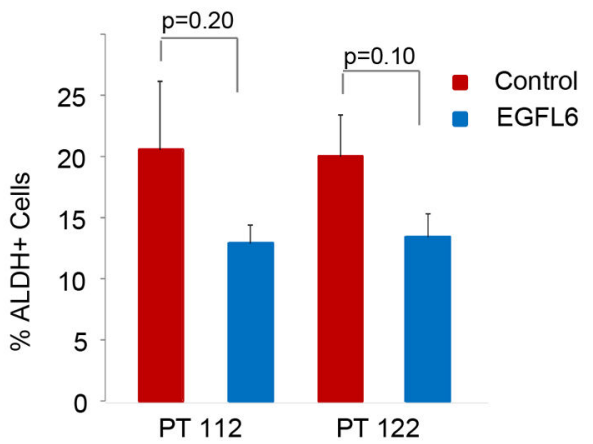

C

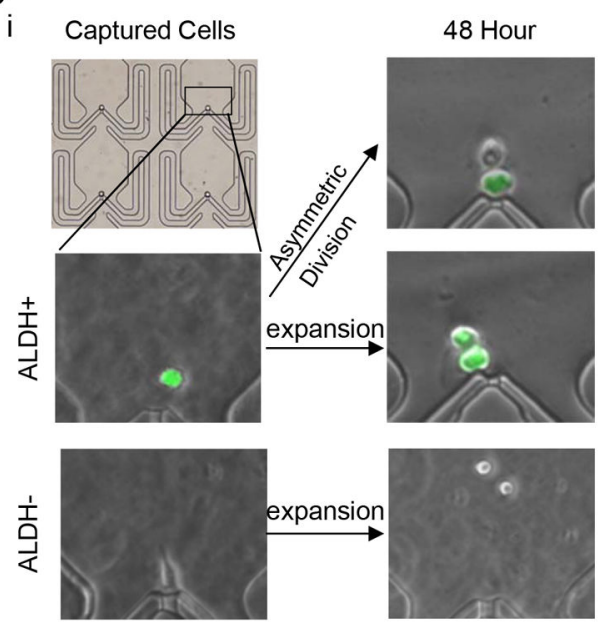

ii asymmetric - Control

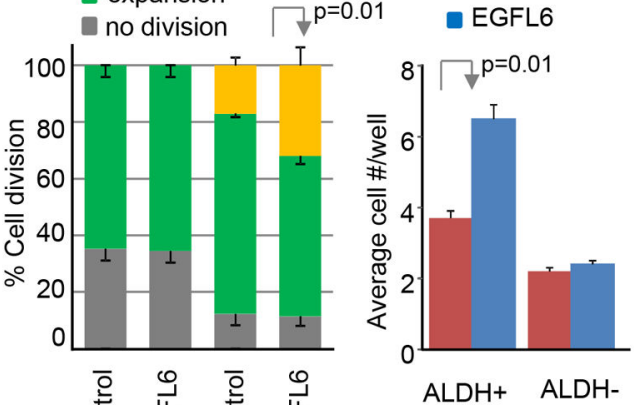

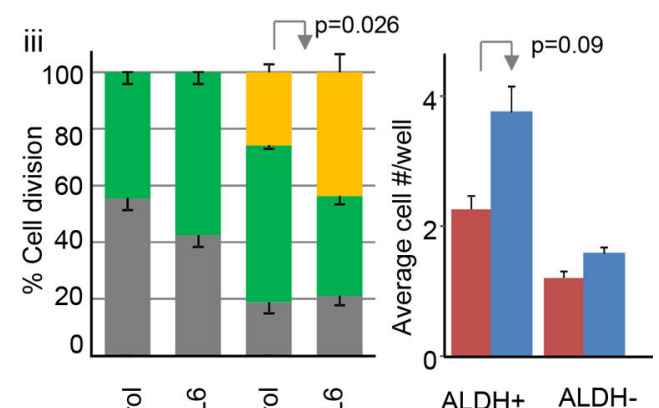

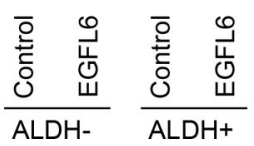

Figure 3. EGFL6 promotes ALDH ${ }^{+}$cell asymmetric division

A. Summary of 3 replicate experiments demonstrating EGFL6 treatment is associated with, (i) increasing total cell numbers, (ii) decreasing percentages of $\mathrm{ALDH}^{+}$cells, but (iii) no change in absolute $\mathrm{ALDH}^{+}$cell number. B. Percentages of $\mathrm{ALDH}^{+}$primary ovarian cancer cells following treatment with EGFL6 or vehicle. C. Single cell microfluidic culture showing, (i) Representative immunofluorescence images demonstrating initial ALDEFLUOR stain $\left(\mathrm{ALDH}^{+}\right.$green, $\mathrm{ALDH}^{(-)}$gray) in captured single cells and the observed types of cell division outcomes for $\mathrm{ALDH}^{(-)}$vs. $\mathrm{ALDH}^{+}$cells after capture, (ii-iii) 
Summary of percentages of division events and average number of progeny/microfluidic well with EGFL6 or vehicle treatment of (ii) SKOV3 cells and (iii) 3 primary patient samples. SKOV3 cells were analyzed in 3 independent experiments. Primary samples were analyzed in 2 independent experiments. 
A

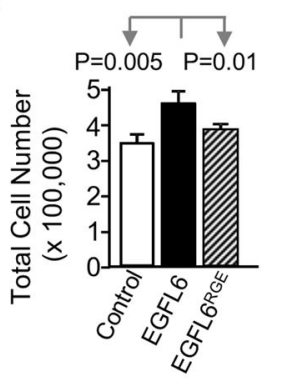

D
B

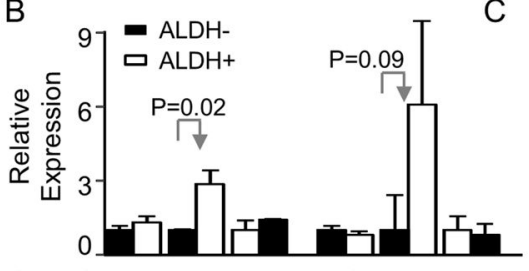

Integrin $\frac{\beta 1 \quad \beta 3 \quad \beta 5}{\text { SKOV3 } 3} \frac{\beta 1 \quad \beta 3 \quad \beta 5}{A 2008}$
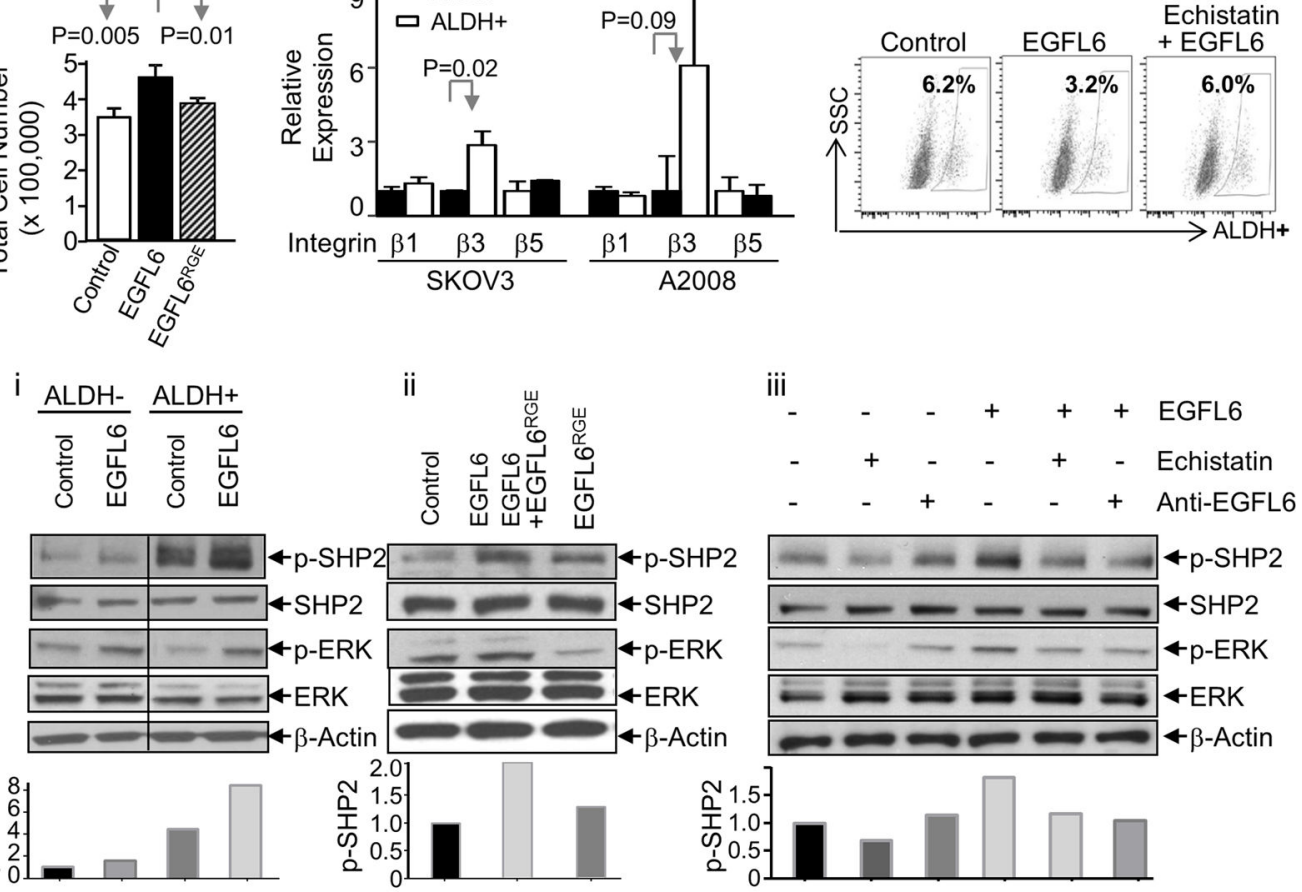

ii

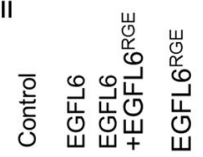

ii
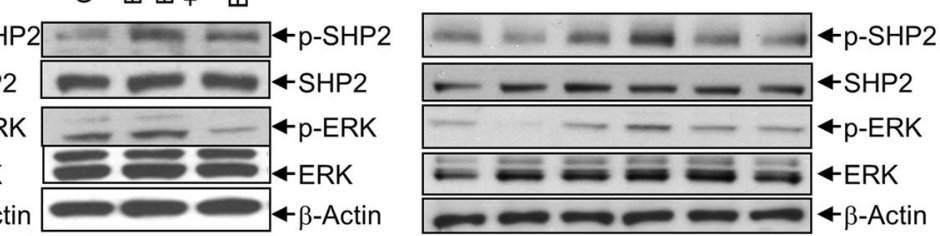

$+\mathrm{SHP} 2$

-p-ERK

$\beta$-Actin
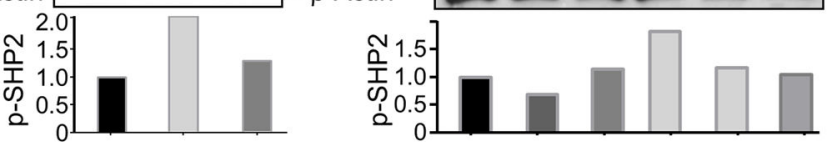

E

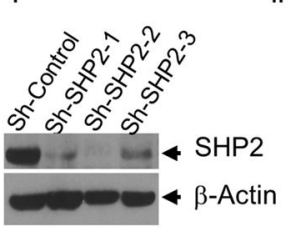

ii

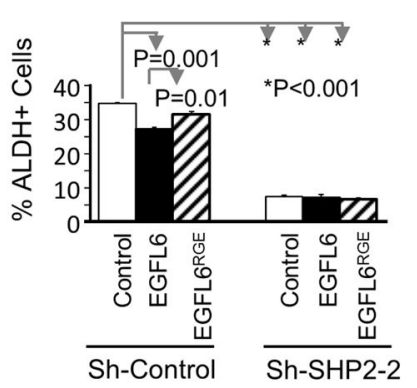

iii

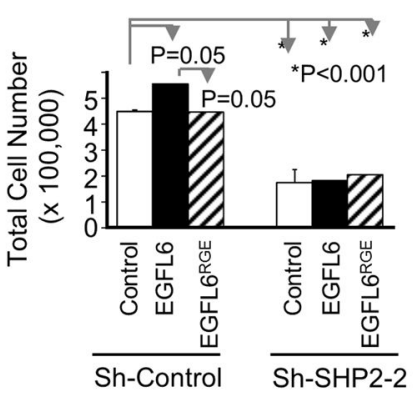

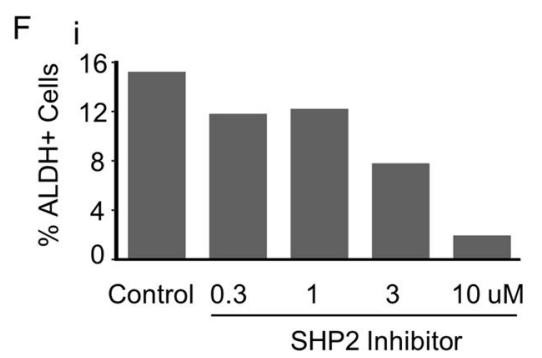

ii

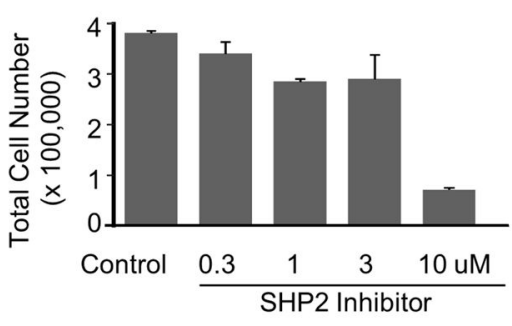

Figure 4. EGFL6 signaling requires Integrin-mediated phosphorylation of SHP2

A. SKOV3 cell numbers after 72 hours of treatment with EGFL6 or EGFL6 ${ }^{\text {RGE }}$. B. qRTPCR demonstrating increased expression of Integrin $\beta_{3}$, but not $\beta_{1}$ or $\beta_{5}$, mRNA levels in $\mathrm{ALDH}^{+}$vs. $\mathrm{ALDH}^{(-)}$ovarian cancer cells. C. FACS plot demonstrating the Integrin $\beta 1 / \beta 3$ competitive inhibitor Echistatin inhibits EGFL6-mediated reduction in $\mathrm{ALDH}^{+}$cell percentages. D. Western blot analysis of the indicated proteins with and without EGFL6 treatment demonstrating (i) SHP2 is preferentially phosphorylated in $\mathrm{ALDH}^{+}$cells and EGFL6 further increases SHP2 activation in ALDH+ cells. EGFL6 treatment is associated 
with increased p-ERK in both $\mathrm{ALDH}^{+}$and $\mathrm{ALDH}^{(-)}$cells, (ii) EGFL6 ${ }^{\mathrm{RGE}}$ mutant does not increase p-SHP2 or p-ERK, (iii) EGFL6-mediated SHP2 and ERK phosphorylation is suppressed by Echistatin and anti-EGFL6 treatment. Bar graphs below graphs indicate densitometric quantification of p-SHP2. E (i) SHP2 western blot of three independent SHP2 shRNA (Sh-SHP2), (ii) ALDH percentage and (iii) proliferation in Sh-SHP2 cells treated with EGFL6 or EGFL6 ${ }^{\mathrm{RGE}}$. F(i) $\mathrm{ALDH}^{+}$cell percentage and (ii) cell proliferation in SHP2 inhibitor treated cells. All experiments were performed at least twice. Error bars indicate standard deviations. 


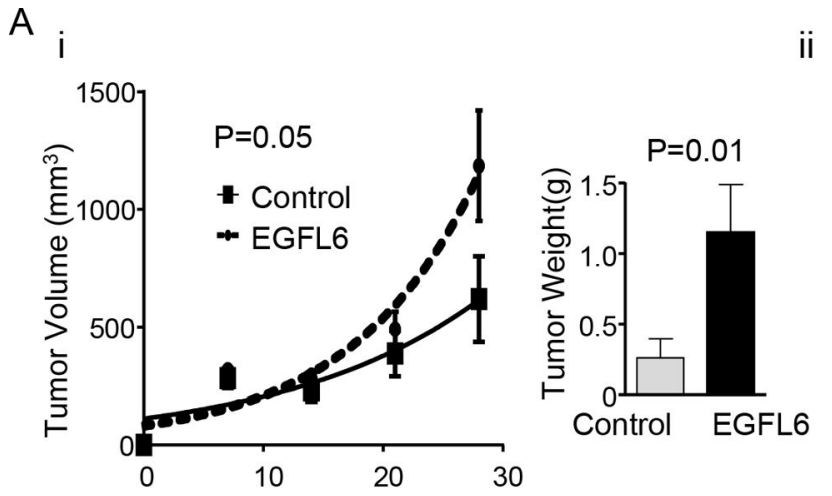

ii

B
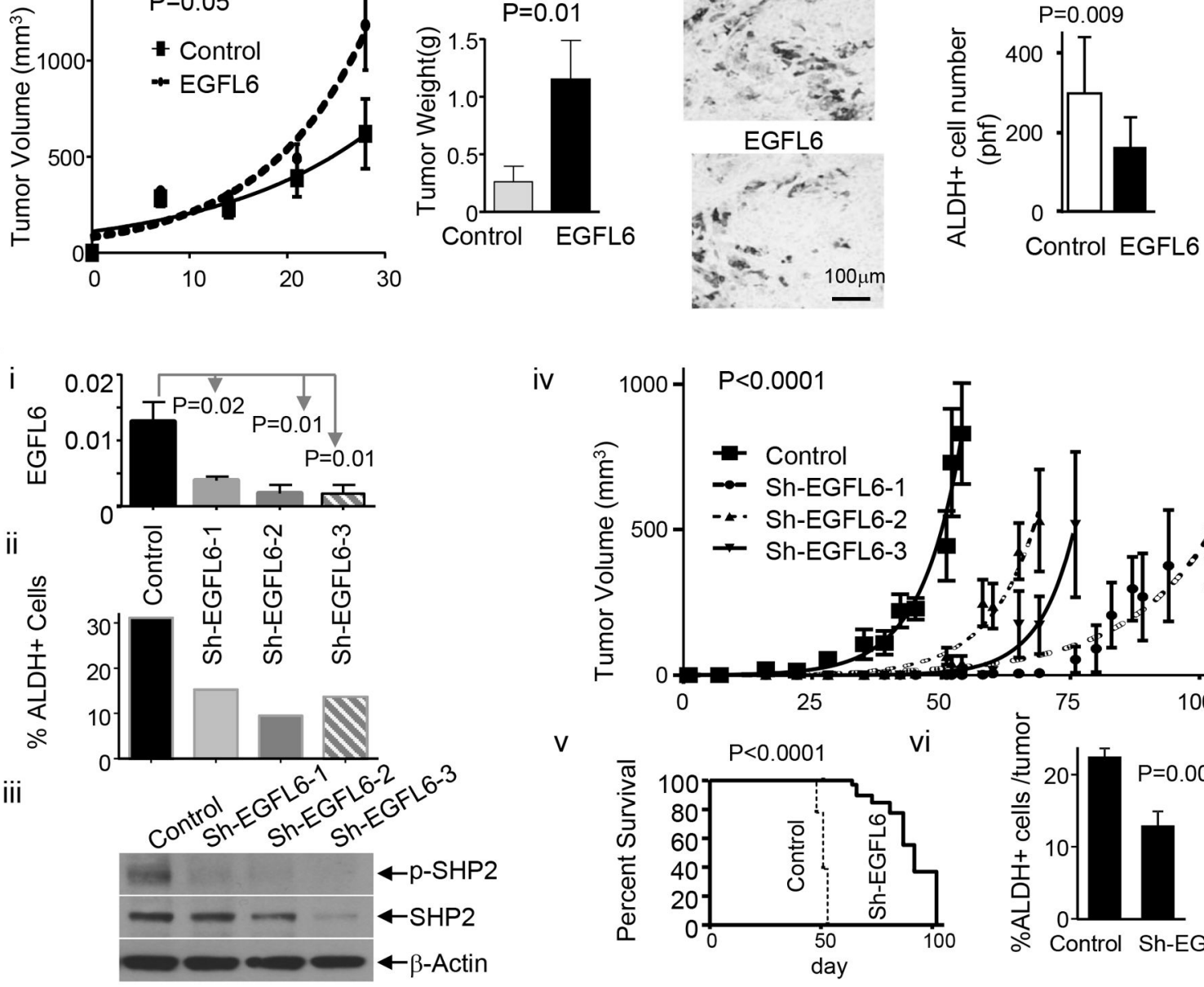

iii

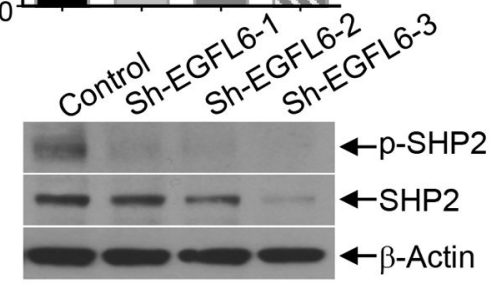

$\mathrm{C}_{\mathrm{i}}$

ii

iii

iv
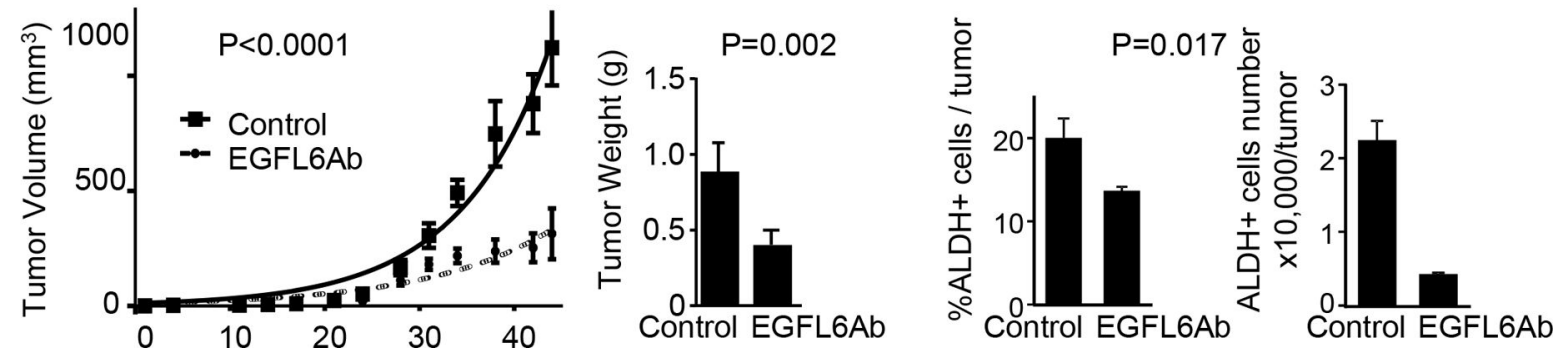

Figure 5. EGFL6 expression in tumor cells promotes ovarian tumor growth

A(i). Tumor growth curves and tumor weights of EGFL6 and control vector-transfected ovarian cancer cells ( $n=10 /$ group in two independent experiments), (ii) IHC analysis and quantification of ALDH1A1 expression in EGFL6 vs. control tumors. B (i). qRT-PCR analysis of EGFL6 expression in control and EGFL6 shRNA knockdown (Sh-EGFL6) NIHOVCAR3 cells, (ii) ALDH FACS and (iii) Western blot analysis in control and ShEGFL6 cells, (iv and v) Tumor growth curves and overall survival for OVCAR3 control $(\mathrm{n}=10)$ and Sh-EGFL6 cells ( $\mathrm{n}=6$ /group). $\mathbf{C}(\mathbf{i}-\mathbf{i i})$ Tumor growth curves and weights, and 
(iii-iv) ALDH+ cell percentages and absolute number for NIHOVCAR3 tumors mocktreated or treated with anti-EGFL6 (EGFL6Ab, n=10/group). Error bars indicate standard deviation. 
A

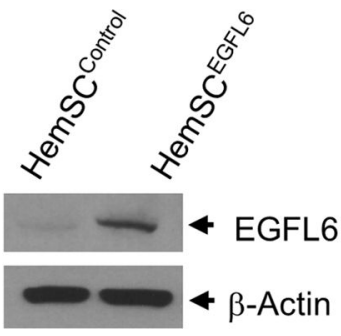

B

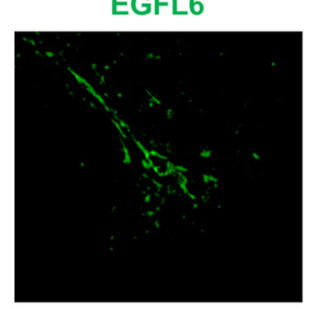

hCD31

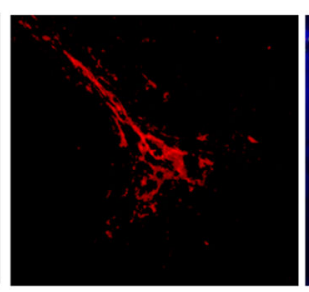

EGFL6/hCD31/DAPI

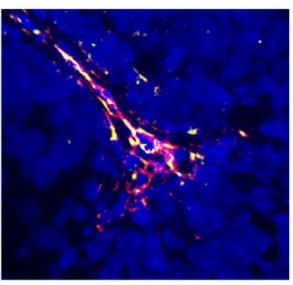

C

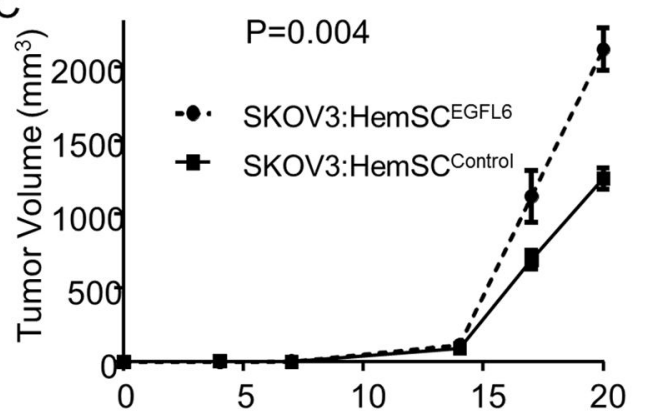

D
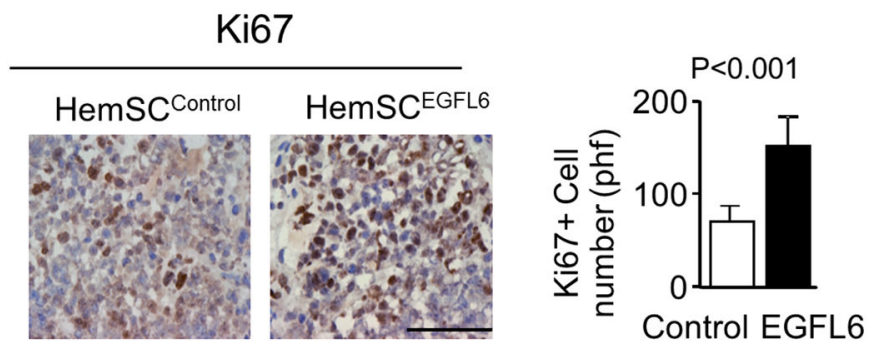

E

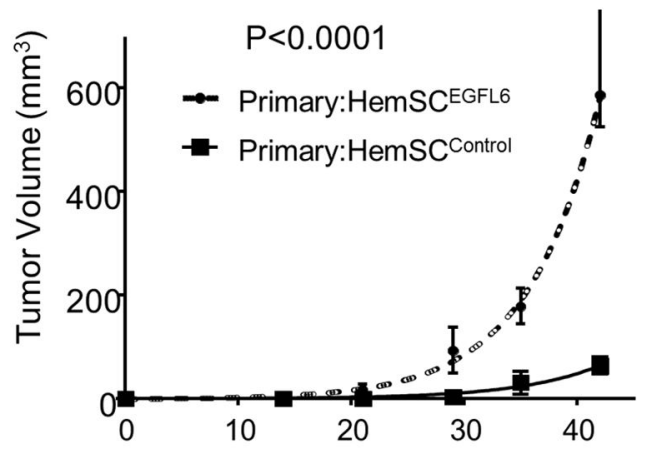

$\mathrm{F}$

HemSCControl HemSCEGFL6

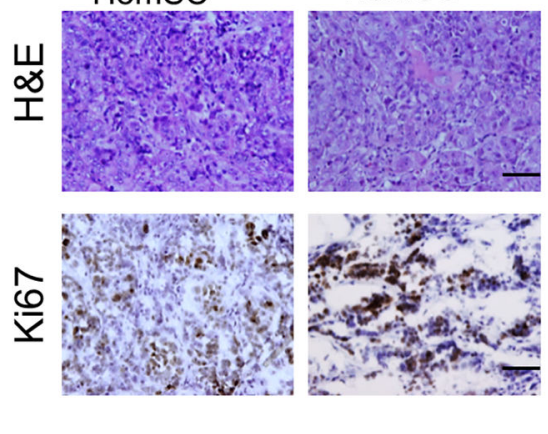

$\mathrm{P}<0.001$

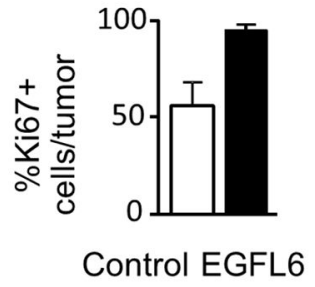

G i

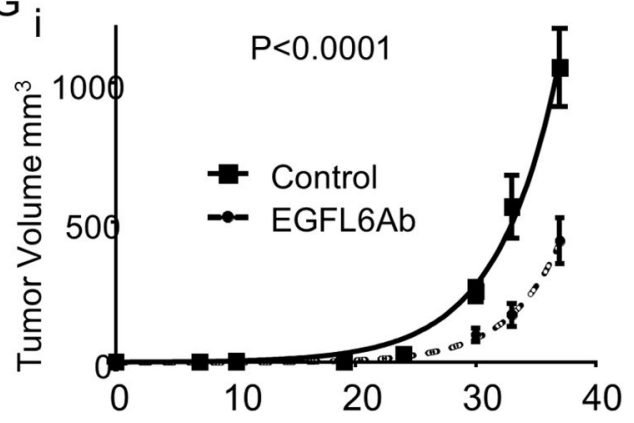

ii

$\mathrm{P}=0.02$

iii

iv
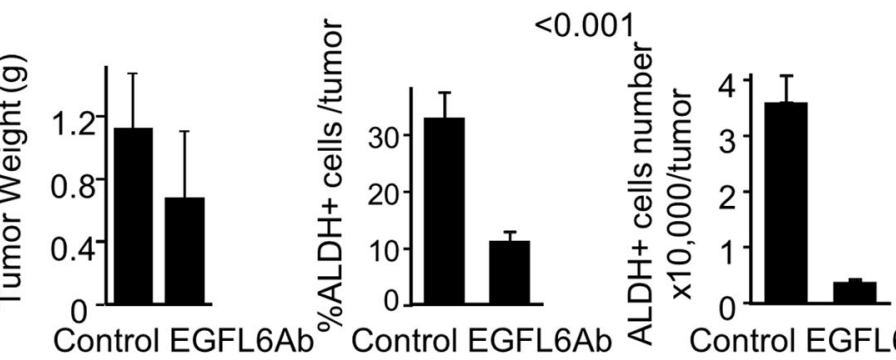

Control EGFL6Ab

Figure 6. Vascular EGFL6 promotes tumor growth

A. EGFL6 Western of control and EGFL6-lentivirally-transduced infantile hemangioma

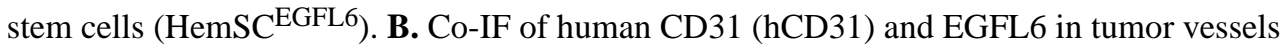
in SKOV3:HemSC ${ }^{\text {EGFL6 }}$ tumor xenografts. C. Tumor growth curves of SKOV3:HemSC EGFL6 tumors vs. SKOV3:HemSC Control tumors ( $\mathrm{n=10/group} \mathrm{in} \mathrm{two}$ independent experiments). D. IHC analysis of Ki67 expression in EGFL6-expressing vs. control tumors. E. Tumor growth curves of freshly isolated primary patient cells co-injected with HemSC ${ }^{\text {EGFL6 }}$ or HemSC ${ }^{\text {Control }}$ ( $n=4$ patients with 2 tumors each). F. H\&E and Ki67 
IHC of tumors generated with primary patient cells co-injected with HemSC ${ }^{\text {EGFL6 }}$ or $\mathrm{HemSC}^{\mathrm{Control}}$ (n=6/group). G. (i) Tumor growth curve, (ii) weights, (iii) $\mathrm{ALDH}^{+}$cell percentage, and (iv) absolute cell number, for control and anti-EGFL6-treated SKOV3 (nonEGFL6 expressing cells) flank tumors ( $\mathrm{n}=10$ /group in two separate experiments). Error bars indicate standard deviations. 
A
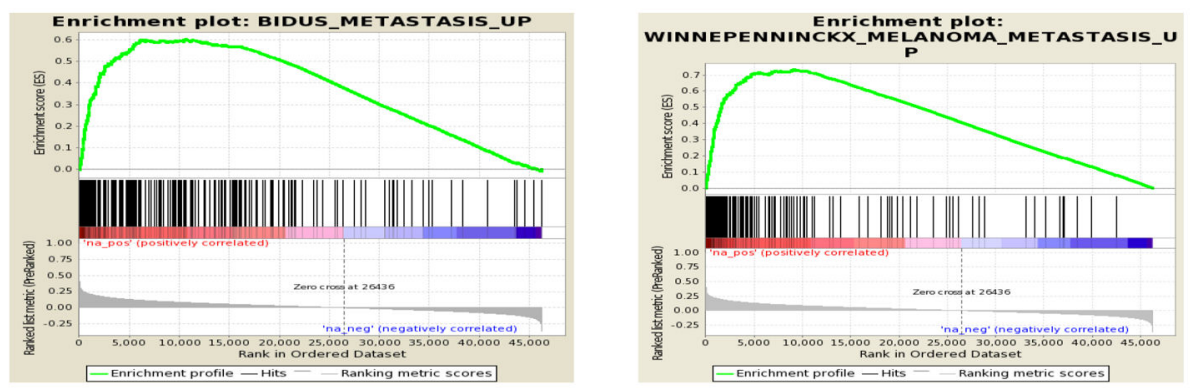

B

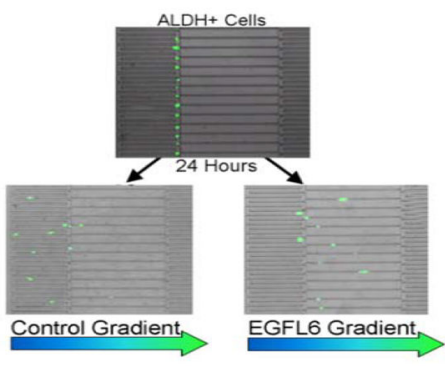

C

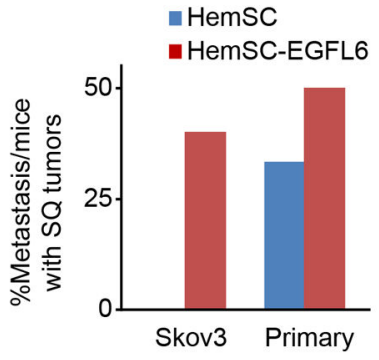

D

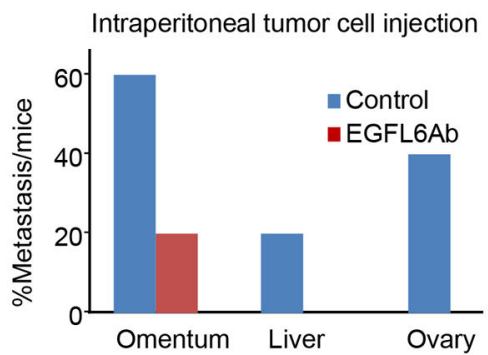

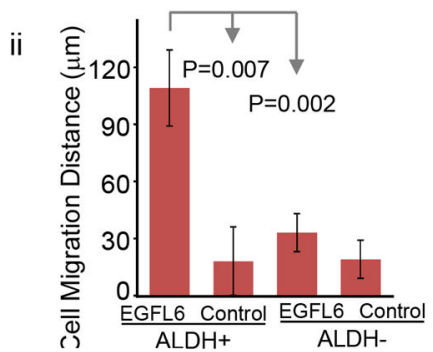

ii

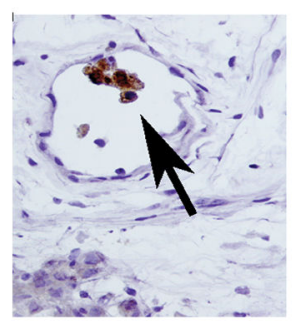

E

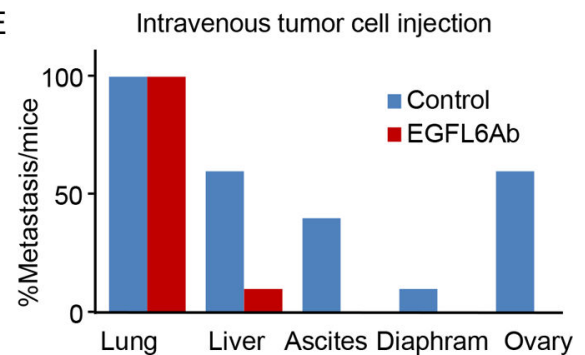

Figure 7. The role of EGFL6 in ovarian cancer metastasis

A. GSEA demonstrating EGFL6 expression correlated with metastatic gene signatures in endometrial ovarian cancer and melanoma. (See Suppl.Fig1C for ES scores, p-values, and FDR q-values.) B(i) Immunofluorescent GFP labeled ALDH ${ }^{+}$SKOV3 cells after capture (top) and migration (bottom) in microfluidic migration device. Control cells (bottom left) have no gradient vs. EGFL6 gradient (bottom right), (ii) summary of distance migrated for the indicated cells from replicate experiments. C (i) Percentage of mice with identifiable metastases when SKOV3 cells or primary human ovarian cancer cells were grown 
subcutaneously (SQ) combined with HemSC Control or HemSC ${ }^{\text {EGFL6 }}$, and (ii) IHC

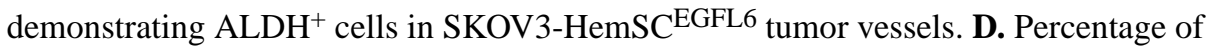
metastasis to the indicated body sites in mice injected intraperitoneally with SKOV3 mocktreated (control) or treated with anti-EGFL6. E. Percentage of mice with metastasis to the indicated body sites in mice injected intravenously with SKOV3 cells and mock-treated (control) or anti-EGFL6-treated cells ( $\mathrm{n}=10$ /group in 2 separate experiments). 